\title{
Employment Dynamics and Business Relocation: New Evidence from the National Establishment Time Series
}

\author{
David Neumark, Junfu Zhang, and Brandon Wall*
}

March 2006

\begin{abstract}
We analyze and assess new evidence on employment dynamics from a new data source - the National Establishment Time Series (NETS). The NETS offers advantages over existing data sources for studying employment dynamics, including tracking business establishment relocations that can contribute to job creation or destruction on a regional level. Our primary purpose in this paper is to assess the reliability of the NETS data along a number of dimensions, and we conclude that it is a reliable data source although not without limitations. We also illustrate the usefulness of the NETS data by reporting, for California, a full decomposition of employment change into its six constituent processes, including job creation and destruction stemming from business relocation, which has figured prominently in policy debates but on which there has been no systematic evidence.
\end{abstract}

\footnotetext{
* The authors are, respectively, Professor of Economics, UCI, Research Fellow, and Research Associate, Public Policy Institute of California (PPIC). Neumark is also Senior Fellow at PPIC, Research Associate at the NBER, and Research Fellow at IZA. We are grateful to Don Walls, an anonymous referee, and seminar participants at PPIC, the NBER Summer Institute, the Hudson Institute, and the $4^{\text {th }}$ Annual IZA/SOLE Transatlantic Meetings of Labor Economists for helpful comments. Any views expressed are those of the authors alone, and not of the Public Policy Institute of California.
} 


\section{Introduction}

Employment growth is a major goal of economic policy at both the national and regional levels. Changes in employment are driven by job creation and job destruction, which in turn are made up of six dynamic processes including the birth, death, growth, contraction, and relocation of business establishments. This "demographic" characterization of business establishment and employment dynamics emphasizes that employment change in an economy is the net result of six influences - three that create jobs (births, expansion, and in-migration) and three that destroy jobs (deaths, contractions, and out-migration). Ultimately, we need to understand all six of these dynamic processes to characterize employment change in an economy, and to identify the job creation and destruction processes on which it might be most productive for policymakers to focus in encouraging employment growth. ${ }^{1}$ Moreover, the fact that employment change is the net result of potentially large gross changes - for example, overall expansion of jobs at existing establishments and overall contraction of jobs at other existing establishments - suggests that what often appear as relatively moderate overall changes in employment over time may mask potentially volatile gross job flows. This implies that relatively small changes in any of the gross flows can lead to sharp changes in net job growth.

But tracking a large population of business establishments across time and space, including births, deaths, and relocations, is difficult and costly, and thus data have not been available with which to fully capture the underlying processes of employment dynamics. Primarily for this reason, although the importance of understanding the job creation-destruction process has long been widely recognized (e.g., Schumpeter, 1942, Chapter 7), systematic empirical research on this topic did not start until quite recently as researchers began to develop appropriate data sources. However, this research has continued to face significant limitations imposed by the data.

In this paper we help introduce a new data source - the National Establishment Time Series (NETS) - which we believe is the first data set that permits a full decomposition of the sources of

\footnotetext{
${ }^{1}$ Strictly speaking, whenever we refer to "employment" measured at the establishment level, we should refer to "jobs," because workers can have jobs with more than one employer. But since "job change" usually conveys a different meaning than "employment change," we usually refer to employment instead.
} 
employment change in regions of the U.S. economy, and which offers other advantages relative to existing data sources. Our primary emphasis is on assessing the reliability of the NETS data along numerous dimensions. We provide this detailed assessment because the NETS data should prove useful to researchers in many fields, but it is a new data source of unknown quality, and we know that there are inherent difficulties in tracking business establishments - especially new establishments and those that relocate. In general, we conclude that the NETS is a reliable data source although not without limitations, and we provide some guidance on its use. We also illustrate the usefulness of the NETS by using data for the entire state of California to fully decompose employment change into its six constituent processes, documenting the importance of each in contributing to employment change and its volatility. Because a principal advantage of the NETS data is the tracking of business establishment relocations, we focus on the role of relocation in employment dynamics. This analysis contributes hard evidence to a policy debate over business relocation that has been entirely speculative and reliant upon anecdotal evidence.

\section{The NETS Database}

\subsection{Overview}

The NETS database is a new longitudinal file based on recent D\&B data. It is a long-term project of Walls \& Associates in conjunction with Dun and Bradstreet (D\&B). We currently have access to an extract of this data set that covers all business establishments that were ever located in California between 1989 and 2002, and their respective parent headquarters (regardless of location). ${ }^{2,3}$

The version of the NETS database that we use begins with 14 cross-sectional files of the full Data Universal Numbering System (DUNS) Marketing Information (DMI) file for each year from 1990 through 2003, each of which covers the previous year. From here on, we refer to the year covered by the

\footnotetext{
${ }^{2}$ An observation in the NETS data is an "establishment." An establishment is a business or industrial unit at a single physical location that produces or distributes goods or performs services, for example, a single store or factory. Many firms own or control more than one establishment, and those establishments may be located in different geographic areas and may be engaged in different industries. We will sometimes refer to an establishment as a "business," reserving the word "firm" to refer to what may be collections of many establishments. While the NETS database is based on information collected at the establishment level, it also uses the Data Universal Numbering System (DUNS) to indicate the relationships among establishments in multi-establishment firms.

${ }^{3}$ Data are available for the entire country, but cost precluded purchasing the entire file. A two-year license for the California file we use in this paper costs $\$ 15,000$; a similar license for the entire file would cost in the range of $\$ 200,000$.
} 
data, i.e., 1989-2002 for the full sample period. The primary purpose of D\&B's data collection effort is to provide information on businesses to the business community, in order to enhance their decision-making by constructing a set of "predictive indicators" (e.g., the D\&B Rating and PayDex scores), and for marketing purposes. The DMI file for each year is constructed from an ongoing effort to capture each business establishment in the United States in each year (including nonprofits and the public sector). The DMI file is based on a multi-layered process incorporating many data sources.

D\&B strives to identify and assemble information on all business establishments, through a massive data collection effort, including over 100 million telephone calls from four calling centers each year, as well as obtaining information from legal and court filings, newspapers and electronic news services, public utilities, all U.S. Secretaries of State, government registries and licensing data, payment and collections information, company filings and news reports, and the U.S. Postal Service. ${ }^{4}$ Particular efforts are devoted to identifying the births and deaths of establishments. For every establishment identified, D\&B assigns a DUNS number as a means of tracking the establishment. It should be pointed out that since around 1990, the DUNS has become the standard means of tracking businesses, having been adopted by many government agencies in the United States and internationally. ${ }^{5}$

Although the goal of D\&B is not to collect and organize data for scholarly research, it does have an incentive to ensure the accuracy of its data, because inaccuracies would hurt D\&B's business and might even result in lawsuits. D\&B has established a sophisticated quality control system and engages in extensive quality and consistency checks. ${ }^{6}$ Thus, the data in each cross-section should provide high quality "snapshots" of business establishments.

Walls \& Associates entered into a collaboration with D\&B with a very different purpose namely, to provide a dynamic view of the U.S. economy using the data from the D\&B archives (Walls \& Associates, 2003). This requires linking the D\&B cross-sections into a longitudinal file that tracks every establishment from its birth, through any physical moves it may make, capturing any changes of

\footnotetext{
${ }^{4}$ See http://mddi.dnb.com/mddi/story.aspx (viewed on April 28, 2005). The information from the U.S. Postal Service includes the National Change of Address database of all changes of address in the United States.

${ }_{6}^{5}$ See, for example, http://www.dnb.co.in/whoduns.htm (viewed on May 11, 2005).

${ }^{6}$ See http://www.dnb.com/us/about/db_database/dnbinfoquality.html (viewed on April 28, 2005).
} 
ownership, and recording the establishment's death if it occurs. This is a multi-stage process, the most important steps of which include merging the data files, imputing data when data are not reported, ${ }^{7}$ eliminating duplicate records, merging records on establishments for which the DUNS number changes (which happens occasionally) yet which appear to cover the same establishment, and identifying establishment relocations.

The resulting NETS database includes the following variables that are of particular importance to this research: current business name; current establishment location (street addresses and phone numbers); FIPS county codes in each year; type of location (single location, headquarters, branch) in each year; employment in each year; and four-digit Standard Industrial Classification (SIC) codes that are also disaggregated to an eight-digit level by D\&B. ${ }^{8}$ Because the NETS reports establishment location for every year, it is possible to infer moves through changes of address.

One highly desirable feature of the NETS database is that it covers essentially all establishments. This reflects the fact that it is designed to capture the universe rather than a sample of establishments. Over the sample period of 1989-2002, the database includes information each year on between 1.2 and 1.8 million establishments in California providing about 15 million to 18 million jobs. In total, more than 3.5 million establishments are covered in our extract of the NETS database.

As the preceding discussion indicates, the data construction effort - including both the crosssectional files and the longitudinal linking that tracks establishments over time - is a massive and complicated one. For this reason, we have undertaken a good deal of investigation to document and examine the quality of the NETS data in order to assess their reliability, potential limitations, and how these limitations might affect results of various analyses.

\subsection{Classification of relocations, births, and deaths}

A central question for using the NETS data to calculate decompositions of employment change into its constituent processes is how $\mathrm{D} \& \mathrm{~B}$ distinguishes whether an establishment at a new location

\footnotetext{
${ }^{7}$ The file indicates when data are imputed.

${ }^{8}$ There is also a detailed cross-walk between these 8-digit codes and the North American Industry Classification System (NAICS).
} 
previously existed elsewhere - and hence will be labeled a relocation in the longitudinal file - or instead is a new establishment. Clearly the correct classification of relocations is critically important in estimating the contributions of births, deaths, and business relocation to job creation and destruction.

In thinking about classifying relocations, a key point is the centrality of the DUNS number to D\&B's data system. It is the DUNS number, after all, that allows D\&B to attach information on credit histories and marketing databases, which is what its clients value. Consequently, DUNS numbers are unique, and D\&B never recycles numbers. If an establishment closes, its DUNS number goes into an "out of business or inactive" file, where it remains permanently unless that business reopens. Each time D\&B updates establishment information, it attempts to contact the establishment based on the previous location information on the establishment. Moves can be indicated in a number of ways. Frequently there is a forwarding address or telephone number, or continuing email contact that allows D\&B to identify a new location. (In addition, business establishments sometimes notify D\&B of their move.) Most important, any establishment that cannot be contacted at the previous year's address or telephone number also goes into the "out of business or inactive" file, and before any "new" establishment can be given a DUNS number, it must be checked against this file, and if there are indications of a match, follow-up investigation is undertaken. For example, if an establishment belonging to a multi-unit firm cannot be found, D\&B contacts the headquarters to determine whether a relocation has occurred. In any case in which D\&B finds that the establishment previously existed elsewhere, it assigns its existing DUNS number. Finally, if a new establishment is identified whose characteristics do not match those of an existing establishment, D\&B contacts the establishment to verify its start date, and assigns a new DUNS number. With these procedures, the longitudinal file should correctly identify relocations of establishments and distinguish them from births of new establishments (and deaths of others), although of course one cannot rule out the possibility of occasional errors of a move being classified as a death in one location and a birth in another, which would lead to an undercount of relocating establishments. ${ }^{9}$ As a

\footnotetext{
${ }^{9}$ Most of the information in this paragraph was supplied by Don Walls and confirmed by him with D\&B (personal communications, May and July, 2005).
} 
consequence, in our assessment of the NETS data we focus in part on accurate identification of relocating establishments.

An establishment relocation in the NETS data is identified by street address and zip code changes from one year to another. Both establishments that moved out of California and establishments that moved into California are included in the database, so we are able to track cross-state relocation.

However, there are some limits to what this form of relocation can tell us about the dynamics of employment change, as other types of changes in employment might be viewed as sharing features of establishment relocation, or reflecting the same forces that drive relocation. First, if a California company sets up an establishment in another state, that establishment does not show up in our extract. That is, we can study establishments that "move out" but not those that "branch out." regarded as equivalent to the former because branching out does not necessarily occur at the cost of creating an additional establishment within the state. Second, the NETS database only tracks physical establishment relocation. There are several other types of relocation that it does not capture by design. For instance, it does not allow us to determine when specific jobs or positions are shifted between two discrete locations of the same firm. This type of relocation, which also constitutes a relocation of jobs between establishments, will be observed in our data set as employment expansion at one establishment and contraction at another. Also, relocations that involve the consolidation of activities at two or more locations into a single location will often be missed, and will be reflected in one establishment growing and another closing. Despite these caveats, the NETS database enables empirical research that represents a significant step towards understanding the role of business relocation in job creation and destruction, especially given that the policy debate frequently refers to physical relocations of business establishments.

\subsection{Advantages of the NETS}

The NETS is not the first data set with which researchers can study employment dynamics, nor is this the first project to attempt to study this question using data from D\&B. However, other data sources present important limitations in studying employment dynamics, and previous work using earlier D\&B

\footnotetext{
${ }^{10}$ With the full national NETS database one can do this, of course.
} 
files has been criticized. See Table 1 for a summary of alternative data sources and findings for the United States, and Neumark, et al. (2005a) for more detailed discussion of past research using these data sources. ${ }^{11}$

Compared with alternative data sources for the United States, the NETS has a few key advantages. First, from the perspective of fully characterizing employment change, the NETS captures business relocation. Unlike most other data sources described in Table 1, the NETS database tracks business address changes and identifies business moves over time within the entire country. As discussed below, this is important because business retention and attraction issues are often at the center of policy debates at the state (and local) level.

In addition, the NETS offers significant advantages in actually carrying out research on employment dynamics (or other topics). Access to the alternative data sources collected by federal and state government agencies is highly restricted because of confidentiality reasons, and hence requires a long and complex process of application and approval. As a practical matter, this has deterred many researchers from pursuing research with these data, and has clearly made it difficult to do research in a timely manner. In addition, again because of confidentiality, researchers working with these data sources are restricted in the geographic detail to which they can disaggregate in describing results. And this confidentiality extends to studying and certainly extends to identifying particular companies. With the

\footnotetext{
${ }^{11}$ There is also related data available for studying employment and business establishment dynamics in other countries. The work with which we are aware focuses to a large extent - although not exclusively - on the role of small firms or establishments in job creation, as originally considered for the United States by Birch (1987) and Allaman and Birch (1975), and then reconsidered by Davis, et al. (1996). Examples of this work include: Davidsson, et al. (1998), who study a plant-level data set for Sweden compiled by the authors based on registers of all business establishments from Statistics Sweden; Broersma and Gautier (1997), who use data on a sample of manufacturing firms in the Netherlands; Baldwin and Picot (1995), who use longitudinal data on Canadian manufacturing establishments from Statistics Canada's Census of Manufactures; and Bednarzik (2000), who reports some results for 10 European countries based on Eurostat data on small- and medium-sized enterprises. The only study we have found that looks at relocation decisions is a paper by van Dijk and Pellenbarg (2000) studying firm relocation in the Netherlands, based on data from Chambers of Commerce throughout the country. It appears that the business register data (as in Sweden) most closely parallel the type of data available in the NETS and other U.S. datasets.
} 
NETS data, in contrast, none of these problems arise. The data are accessible and there are not confidentiality restrictions imposed on users. ${ }^{12}$

\section{Assessment of NETS Database}

We use three strategies to assess the reliability of the NETS data. First, we compare the NETS data with alternative data sources that are publicly available to assess the accuracy of measurements of employment levels and changes. Second, we search business relocation cases reported in the media and check whether they are captured by the NETS data. And third, we use phonebooks and company web sites to try to identify business establishment births and assess the accuracy with which the NETS tracks such births.

In all cases, the reader is reminded that there are complexities involved in each of these measurement exercises, and it is not clear that any one particular data source is the "gold standard." Thus, our analysis does not focus solely on whether the NETS "measures up" to these other data sources, but instead discusses the strengths and weaknesses of each and the degree of correspondence between them. There is a lot more to learn about these measurement differences, and we suspect that the potential advantages of the NETS will spur further assessments that build on those we carry out here.

It is important to note that there was a dramatic change in the data collecting process at D\&B in 1991. In particular, on July 25, 1991, a federal court ruling allowed regional Bells to sell information they collected (United States v. Western Elec. Co., 767 F. Supp. 308 (D.D.C., 1991)). In 1992, therefore, D\&B started to use yellow pages to identify business units, which greatly expanded its database. This resulted in a significant surge in the number of establishments and jobs in the NETS data in that year, which we expect to have seriously mitigated earlier problems with coverage by the D\&B data. Consistent with this, as we show below, the D\&B data now detect more very small establishments than do other data sources. From this point on, we will drop the 1989-1991 data and focus on the 1992-2002 sample period.

\footnotetext{
${ }^{12}$ Although the NETS data are expensive, the time plus money costs appear quite favorable, compared to using the alternative data sources, which as noted are very difficult to access, and also require payment of "substantial user costs" to the Census Bureau (see http://webserver01.ces.census.gov/index.php/ces/1.00/researchguidelines, viewed on March 22, 2006); these can range into tens of thousands of dollars per year.
} 


\subsection{Measurement of employment levels}

One approach to assessing the NETS database is to compare its estimates of employment levels and changes with similar estimates from other sources. The data products that can be used for these comparisons are the Quarterly Census of Employment and Wages (QCEW), the Current Employment Statistics (payroll) survey (CES), and the Size of Business data (SOB). The QCEW and SOB are based on ES-202 data. ${ }^{13}$ Consequently, these two sources exclude the self-employed, proprietors, domestic workers, unpaid family members, and some other groups. The CES covers all nonfarm payrolls. These data sets only provide aggregate statistics at various geographic, industry, or establishment size levels, and thus it is only at these levels that we can compare the data sources. ${ }^{14}$

We begin by comparing employment level measurements in the NETS to those in the QCEW and the CES. We use 1997-2000 for the comparison with QCEW data because earlier years were not readily available, and subsequent years use the North American Industrial Classification System (NAICS) instead of SIC codes, and hence cannot be directly compared. We use the full sample period for the CES comparison. For both sources, we do this at the most disaggregated level at which QCEW data are publicly available for all counties - by county and one-digit SIC industry. ${ }^{15}$ Figure 1 plots the data for the alternative measurements of employment by county and industry from the NETS and the QCEW. If the measurements agreed exactly, then they would all lie on a 45-degree line, which is drawn in the figure. It is clear from visual examination of the figure, as well as the very high computed correlation of 0.994, that employment levels in these two data sources correspond very closely. On the other hand, the points actually lie on a line that is flatter than the 45-degree line, implying higher employment levels in

\footnotetext{
${ }^{13}$ The ES-202 program, formally known as the Covered Employment and Wages program, is a joint effort of the Bureau of Labor Statistics (BLS) and state employment security agencies. Using quarterly data collected by the state agencies, BLS summarizes employment and wage data for workers covered by state unemployment insurance (UI) laws and for civilian workers covered by the Unemployment Compensation for Federal Employees (UCFE) program. The ES-202 program provides a comprehensive and accurate source of data on employment and wages, by industry, at the national, state, and county levels (U.S. Bureau of Labor Statistics, 1997, Chapter 5).

${ }^{14}$ The publication of employment/establishment data is sometimes withheld in order to protect the identity of cooperating employers. For example, QCEW is suppressed if there are fewer than three establishments in a cell, or if a single employer makes up more than $80 \%$ of the employment in that cell.

${ }^{15}$ Data at finer levels of industry disaggregation are often suppressed at the county level for reasons of confidentiality.
} 
the NETS. ${ }^{16}$ We return to this issue below. We constructed a similar figure for comparing employment measurements in the NETS with those in the CES data. It reveals a similar pattern, and also a high correlation (0.948).

To assess the quality of employment measurements in the NETS by establishment size, we also examined the correspondence between employment as measured by the NETS and the SOB; for this latter source employment can be measured by industry and size of establishment (as well as county, of course) as can also be done in the NETS database. Here the data correspond less well, and the correlation falls to 0.817. Looking at employment by establishment size shows that the greater discrepancies reflect the fact that the NETS database has much higher coverage of small establishments than does the SOB.

Part of the disparity in employment and the number of establishments indicated by the SOB and NETS data sets for small establishments might be driven by the fact that business owners are typically excluded from coverage under the ES-202 unemployment insurance system (although they are permitted to pay UI taxes and be covered). ${ }^{17}$ This could be quite important for the smaller establishments in which single owners can represent a sizable share of total employment. So the comparison is more informative if we remove one employee from each establishment covered in the NETS database, and then reassign NETS establishments to size categories based on the adjusted employment levels. As shown in Figure 2, the adjusted data on the size distribution of establishments in the two data sources indicates relatively similar distributions. But the NETS still captures more employment in the smallest size category, and the overall employment discrepancy between the two data sources is $5.0 \%$ (higher in the NETS). ${ }^{18,19}$

\footnotetext{
${ }^{16}$ The points that are farthest off the line, at high employment levels, are for service-related industries in Los Angeles. However, these points actually lie quite close to a regression line through the data.

${ }^{17}$ This same point was noted earlier in work by MacDonald (1985).

${ }^{18}$ Unfortunately, CES does not include a series for the number of establishments. Therefore, a similar comparison of average establishment size is impossible. Because CES is periodically benchmarked to UI universe counts, we would not expect that results would be much different.

${ }^{19}$ In addition, apparently in the NETS data separate lines of business (industry) at the same physical site are sometimes reported as separate establishments, which would tend to create a higher count of establishments of smaller sizes. However, this seems unlikely to be important for very small establishments that are unlikely to operate in more than one industry. Also, note that this should not play a role in the measurement of employment levels, unless there is double counting.

With respect to comparisons of employment counts for the other establishment size categories, a complication is introduced because, as documented below, there is a good deal of rounding of employment levels in the NETS - as it turns out, to the employment levels that are the left-hand "edges" of the size categories into which
} 
Finally, in Table 2 we attempt to account for differences between the NETS database and the SOB data described above by examining employment data for 1994-2002. The first two rows of the table indicate the total employment levels reported in the NETS and the SOB report, respectively, for each year. Since SOB data only include individuals earning wages that are covered by unemployment insurance, several categories of workers that are reported in the NETS, most notably the self-employed and independent contractors, are excluded from the SOB by statute.

To estimate the number of individuals who are either self-employed or independent contractors, we use data reported in the Contingent Work Supplement (CWS) to the Current Population Survey (CPS) in years 1995, 1997, 1999 and 2001, as reported in row 3 of the table. In row 4, we combine the total employment reported in SOB with the number of self-employed and independent contractors from CPS to arrive at an approximate level of household employment in California (which we label SOB+SE/IC). As we see in row 6, our approximation of household employment in California falls short of the level of employment reported in the NETS database for each of the years we examined. It is instructive to note that while the NETS over-reports household employment in comparison to our approximation in row 4 of the table, this approximation itself overstates household employment when compared to the CPS employment figures for each year, as shown in the last row of the table. The differences between the NETS and the SOB+SE/IC series may be partly explained by some self-employed or independent contractors having multiple businesses - all of which should show up in the NETS, but not in the SE/IC series, where an individual is counted only once. On the other hand, this cannot account for the CPS versus $\mathrm{SOB}+\mathrm{SE} / \mathrm{IC}$ difference. ${ }^{20}$

the SOB data are classified $(10,20,50,100,250,500$, and 1000 - but not 5). Consequently, when we eliminate one employee and reassign establishments to size categories based on the adjusted employment level, we get underrepresentation of NETS establishments in the higher SOB category of 1000+, with potentially offsetting overrepresentation and underrepresentation in the lower categories (compare Figures 3 and 4 ). Because of these concerns we should not expect our adjustments to yield a perfect match under any circumstances. However, we also found that the numbers from the NETS after subtracting one employee but without reassignment to size categories, and the numbers with reassignment as well, generally bracket the SOB numbers (except for the smallest establishments), indicating that the NETS data are relatively accurate. Nonetheless, as discussed in the next section, the rounding does have implications for the measurement of employment change.

${ }^{20}$ We carried out a similar comparison using alternative estimates of the self-employed provided by the Census' Nonemployer Statistics, available for some years. Estimates using this method are somewhat closer to the NETS employment levels for most years. This method likely explains more of the gap between the NETS and SOB data 
Overall, these calculations suggest that the NETS estimate of employment (more accurately, the number of jobs) is higher than other sources because it uses a more comprehensive approach. Despite the remaining discrepancies - and note that there are discrepancies among any pair of data sets one chooses to compare - the NETS data appear to measure employment levels relatively accurately.

\subsection{Measurement of employment change}

Next, we turn to measurements of employment change. We first begin by documenting, in Figures 3 and 4, the extent of rounding of employment in the NETS data. These figures show that for both smaller and larger establishments the distribution of the number of employees is disproportionately concentrated on numbers that are divisible by $5,10,100$, and so on. While employment rounding may bias some of our estimations, it is not a particularly serious problem for the measurement of employment levels if we believe that employment numbers are rounded to the closest "salient numbers." In that case, our aggregate levels are unlikely to be biased appreciably, because some people round their numbers up and others round them down, and the establishment-level measurements may contain measurement error that is largely random (although non-classical). It does, however, mean that employment change is "sticky," and that our estimates likely underreport the frequency with which establishments change their levels of employment, thereby underestimating the degree of employment change caused by establishment expansion and contraction.

Another potential source of stickiness in the measurement of employment change in the NETS is imputed data. During 1993-2002, between 55 and 73\% of each year's employment figures are actual data. ${ }^{21}$ The remaining establishment records are imputed - either by D\&B or by Walls \& Associates with the latter occurring when the D\&B imputations were suspect, and attempting to improve on the imputation by using time-series information on the establishment instead of only cross-sectional information. Imputed data are far less common for older establishments. Moreover, once actual

because it allows self-employed individuals to report multiple businesses, as does the NETS database. (See Neumark, et al. (2005a) for details.)

${ }^{21}$ A very small share of these - 1 to $2 \%$ - are reported by D\&B as "bottom of range" rather than actual data, and seem to indicate cases where the responded provided a range for employment rather than a single number. However, judging by the variation in these observations, they behave like actual data and are treated as such in this discussion. 
employment data are provided for an establishment, they are very likely to be provided in all subsequent years. Both of these regularities indicate that imputation is a feature of establishments' earliest appearances in the database. More specifically, establishments that are tracked for a relatively short period of time exhibit a bimodal distribution, with either no years with actual data or all years with actual data. But establishments that are tracked in the data set for a longer period are much less likely to have no years without actual employment data, and conversely have relatively more years with actual data; and the mode is to have actual data for all years. ${ }^{22}$

Together, rounding and imputation of employment data result in infrequent year-to-year changes in employment. Table 3 illustrates this with regard to imputation, showing the incidence of employment change by type of employment data. As we would expect, it is far lower for imputed data. And overall, $7.6 \%$ and $16.3 \%$ of existing establishments reported a change in the number of employees in 1993 and 2002 , respectively, and $19.6 \%$ and $14.1 \%$ of workers were at establishments that reported a change in the number employed in those years - numbers that we suspect are low.

The implication of these measurement problems is that the NETS data compare less favorably with other data sources when we look at employment changes, rather than employment levels, especially for high-frequency (short-term) changes. As shown in Figure 5, the correspondence between NETS and QCEW yearly employment changes by industry and county is not very strong, with a correlation of only 0.528. However, if we look at employment changes over periods of at least a few years, this problem is substantially mitigated; for example, the correlation rises to 0.864 for changes over three-year intervals (Figure 6).

This greater correspondence of employment changes over longer intervals is consistent with what we would expect based on the findings noted above regarding rounding and imputation. With rounding, the data will likely more accurately measure employment changes over a longer period, because rounding results in small changes being ignored but larger changes being measured. Similarly, we saw that imputation tends to be a feature of establishments' first appearance in the data set, whereas over time

\footnotetext{
${ }^{22}$ More detail is given in the working paper version of this study (Neumark, et al., 2005a).
} 
actual data are more likely to be reported and hence employment changes better measured. The implication of these findings is that the NETS database should not be used for measuring very short-term employment changes, but is more useful for measuring employment changes over periods of a few years or more. This does present a tradeoff, however, as an inability to focus on short-term changes inhibits our ability to observe high-frequency changes in job creation and destruction, such as over the business cycle. ${ }^{23}$ We also note that making the unit of analysis for employment change longer affects what proportion of employment change we attribute to job creation and destruction versus establishment expansion and contraction, and to a much lesser extent relocation, a point to which we return below.

\subsection{Tracking business relocations}

A unique feature of the NETS data set is its ability to track establishment relocations. There are no other comprehensive data sets with which to compare measurements of geographic movement of establishments over time to such information in the NETS. Instead, we used Lexis-Nexis to conduct newspaper searches of business relocations involving California establishments, and conducted a detailed comparison of evidence on relocation in the NETS database to evidence found in these searches. Our search was not meant to be exhaustive; it is only intended to obtain a replicable sample of press coverage of specific business relocations.

We describe in detail our results from searching relocation reports in the Los Angeles Times, which has the largest circulation of any California newspaper. The Los Angeles Times has a regional bias in that it focuses on business moves in Southern California, especially the Los Angeles region. Business relocations in other regions are reported only if they are high-profile or reflect a move between the Los Angeles region and the rest of the state. ${ }^{24}$

\footnotetext{
$\overline{{ }^{23}}$ This does not imply that the NETS data are uninformative about high-frequency changes, just that researchers using these data for this purpose need to be cognizant of the measurement error and to think about how it may affect their estimates and conclusions.

${ }^{24}$ We also searched the Kiplinger California Letter, a concise bi-monthly business newsletter that has a section specifically reserved for business relocation reports. Comparing the two sources, as expected Kiplinger California Letter provides more balanced coverage of business moves in different regions in the state.
} 
Using a carefully-designed search algorithm, ${ }^{25}$ we focused on 1,067 newspaper articles from the Los Angeles Times (1996-2000), from which we were able to identify 576 references to specific instances of business relocation, covering 452 unique relocation events. Of these, 237 business relocations were confirmed as valid moves by the NETS database. For the reported relocations not confirmed in the NETS, we undertook thorough efforts to independently verify whether there was in fact a relocation. It turns out to be very difficult to use other information sources to locate the establishments whose relocations are reported in the media but for which there is not an obvious match in the NETS. Ideally we would contact the establishment directly and confirm that the reported relocation occurred. However, this becomes very difficult when establishments (or often, businesses) can be acquired by other firms or for other reasons currently do business under a different name, or no longer exist. Naturally, these problems are more severe in trying to verify reports of relocation that are relatively old. Nonetheless, when possible we contacted the establishments directly. We also searched for company information using Hoovers.com ${ }^{26}$ and Lexis-Nexis Company Information Search - web-based resources that track business addresses and would reveal new addresses for businesses that changed location.

Of the 215 relocations not found in the NETS, 47 were confirmed as "invalid" moves. ${ }^{27}$ Of the remaining 168 reports of relocation that we could not locate in the NETS database, we were able to independently verify that 18 relocations indeed occurred. And not one of the 18 was a cross-state move. Despite our best efforts using the methods described above, we were unable to confirm the remaining 150 reports of relocation from the Lexis-Nexis. And at least $91 \%$ of these businesses (136 out of 150) are captured by the NETS database with no relocation indicated. Furthermore, 92 (68\%) of these

\footnotetext{
${ }^{25}$ We experimented with several search terms. Our final choice of search term - "ATL2(RELOCAT!) AND BUSINESS AND (MOVE OR MOVING OR MOVED) AND (SECTION("BUSINESS") OR

SECTION("METRO"))" - was guided by a desire to exclude irrelevant articles, which we assessed through repeated searches and screening of articles. A detailed appendix describing how we arrived at this search term is available from the authors.

${ }^{26}$ Hoovers.com utilizes the same raw data provided by the DMI file as the NETS database. However, the search mechanism is very flexible, sometimes making it easier to locate establishments that could not be found through company keyword searches in the NETS database.

${ }^{27}$ Five moves turned out to be consolidations of businesses because the establishment at the destination already existed before the move; 17 cases were planned moves but did not occur later; 12 of the establishments at "destination" were new branches instead of relocated businesses; and 13 moves involved establishments such as schools and nonprofits that are not the focus of our research.
} 
establishments were still in existence through 2002, although we were only tracking relocations that were reported between 1996 and 2000. If these establishments had relocated, but not been tracked properly as relocations by NETS, then these establishments would have reported closing years close to the date of the relocation.

Thus, in total, $58.5 \%(237 /\{452-47\})$ of the valid business relocations that we identified from the Los Angeles Times could be found in our NETS data set. This rate of confirmation varies dramatically depending on the distance over which the relocation occurred. We are able to confirm only $27 \%(21 / 77)$ of within-city moves, whereas we are able to confirm $70 \%(177 / 252)$ of between-city, within-state moves, and 74\% (37/50) of cross-state moves. It is neither surprising nor worrisome that the NETS detects only a relatively small share of within-city moves, because short-distance moves are much less significant for the scope of research for which this database is most useful. In fact, many within-city moves occur over such short distances that they could not be identified within the NETS database. For instance, several contacted establishments said that the moves had occurred, as indicated in the newspaper article, but the new location was adjacent to or "across the street" from the previous location. The NETS is designed to only report "significant moves," which are defined as moves where both the street address and zip code information change; this criterion was chosen to avoid mistaking the changing boundaries of zip codes for actual moves. ${ }^{28}$

We do not expect every relocation to appear in Lexis-Nexis, but we do expect all real relocations that are covered in the media to also appear in the NETS. Given the difficulty of checking whether reported cases actually occurred, it is impossible to quantify exactly what share of real relocation is captured in the NETS. But for moves crossing city or state boundaries, we estimate that the share is well over $75 \%$ and probably closer to $100 \%$, based on the fact that most of the cases not captured by NETS cannot be independently confirmed as real relocations. Thus, we conclude that the NETS database does

\footnotetext{
$\overline{{ }^{28} \text { Our search for reports of }}$ business relocation in the Kiplinger California Letter (1996-2001) revealed similar results. Of the 79 incidents of relocation we identified in this search, 12 were found to be misreports of establishment relocation. Of the remaining 67 media observations of relocation, 35 (55\%) were confirmed in the NETS database. In addition, 3 cases were confirmed in Hoovers.com, but occurred too recently to be found in NETS, and 29 cases could neither be confirmed nor denied.
} 
quite a good job of tracking business relocations, with a very low rate of false negatives, although our analysis probably pertains more to larger establishments that would be reported in the media. However, in contemplating the empirical results on establishment relocation discussed later in this paper, one might want to adjust upward modestly the job creation and destruction attributed to relocation.

\subsection{Capture of new business establishments}

Given the concern from earlier research regarding the ability of the D\&B data to track new establishments, and the potential importance of establishment births in job creation, it is also important to assess how well the NETS tracks new business establishments. We do not have access to ES-202 data with which measurement of new establishments can be compared. We therefore first attempted to compare the NETS data to new establishments identified from phonebooks, following the earlier work by Birley (1984). Specifically, we selected a random sample of establishments from the 1999-2001 San Francisco Pacific Bell Business White Pages, and identified businesses that are initially not in the phonebook, but then show up in a later year, as a means of identifying an alternative list of new establishments, drawing a sample of 58 openings. ${ }^{29}$

Of these 58 openings, 52 (90\%) of the establishments could be identified in the NETS database. Many listings were difficult to match because companies often do business under multiple names, and because of differences in spelling or abbreviations. Thus, this matching required that we also try to match using company name keyword search, phone number reverse lookup, address information, or alternate company names provided by workers whom we contacted at the particular establishment. While many of the NETS opening dates corresponded well with those indicated by the phonebook listings, many did not.

\footnotetext{
${ }^{29}$ We randomly chose to start with listings beginning with "B." We have no particular reason to expect a relationship between the name of the business and the likelihood of its inclusion in the NETS database, although we cannot rule this out. Preliminary investigation suggested that business establishments that use initials in their name (such as "B \& G auto rental") may change names from year to year, so we instead began drawing our sample with telephone listings that started with "Ba." We chose enough observations to get approximately 60 new establishments, which required 313 listings that appeared in the phonebook at least once between 1999 and 2001. We excluded 35 records from the analysis because businesses from outside the area code presumably have to pay to be listed in the business white pages, meaning that the appearance or disappearance of such businesses would often occur for reasons unrelated to opening (or closing). These records indicate 58 openings (and 61 closings). There were also three records for which the listing appeared in 1999, was absent in 2000, and reappeared in 2001 with the same name and phone number. This is one indication - more are described below - that the phonebooks do not provide an accurate means of tracking openings and closings.
} 
Given the disagreements, we attempted to obtain each business establishment's opening year directly from the company, or through their website. We were able to obtain approximate start date information from 33 of these 52 establishments. This comparison revealed that many of the opening years that were indicated by changes in phonebook listings were inaccurate, with the phonebook method necessarily assigning these openings to 2000 or 2001, but the actual openings spread over a long span of years. In contrast, the NETS data match opening dates much more accurately, as indicated in Figure $6 .{ }^{30}$ And for those establishments that could not be reached directly, the NETS and phonebooks start dates were generally in agreement, because many of these were young establishments that failed subsequently, so there was not much scope for the start dates to differ. ${ }^{31}$

Given the inaccuracies in openings based on the appearance of businesses in the phonebook, we wanted to check another source for data on establishment openings. ${ }^{32}$ To do this, we carried out a similar exercise for California biotech companies listed in the BioAbility database of U.S. biotech companies. ${ }^{33}$ Because we are assessing how well the NETS captures births, we first chose companies that this database indicated were founded in our sample period for the NETS data (1992-2002), of which there are 300. To be more certain that we had the founding dates correct, we checked the BioAbility founding dates against company websites, retaining only the 161 cases for which the website also reported a founding date. Of these 161 cases, in $89 \%$ (142) the websites reported founding dates that corresponded exactly with the

\footnotetext{
${ }^{30}$ Even if the NETS data were completely accurate, we would not expect an exact correspondence with the start dates obtained from our efforts to contact businesses directly. In our phone calls, we often talked to employees who had limited tenure and did not know the founding date, in which case we were only able to obtain information that provided a lower bound for the number of years that a particular establishment had been in business.

${ }^{31}$ As another check on the NETS data, we also attempted to locate NETS records for business establishments that were listed in the San Francisco phonebook for all three years. If NETS records indicate opening or closing years within 1999-2001, then we might be concerned that NETS is inaccurately reporting the timing or incidence of openings or closings. We randomly chose 72 of the 156 records in the phonebooks in all three years, and we were able to locate $66(92 \%)$ in the NETS database, which represents a slightly higher percentage than those that we could identify from the earlier subset of phonebook-inferred openings. Of these records, according to the NETS data all but 6 continued to exist through 2002 and only one record indicated a closing by 2001, indicating a close correspondence between the NETS and phonebook data for continuing establishments.

${ }^{32}$ For the same reason, coupled with the difficulty of verifying information directly with businesses that have closed, we deemed the phonebook method inappropriate for assessing the ability of the NETS data to identify establishment closings.

${ }^{33}$ This is a database of more than 2,000 U.S. biotech companies (based on a relatively narrow definition of biotech) maintained by BioAbility, a biotech consulting firm. See http://www.bioability.com/us_biotech_companies.htm (viewed on September 14, 2005).
} 
start year listed in the BioAbility database. If they did not match, we used the date from the company website, presuming that this was more accurate.

We then checked these founding dates against the appearance of these companies in the NETS to determine how well the NETS captures births. Only 8 of these 161 companies could not be located in the NETS database. ${ }^{34}$ Of the remaining 153 records, $75 \%$ (114) of the start dates listed in the NETS corresponded exactly with the company start dates reported on the web site, $88 \%$ (135) fell within one year, and 92\% (141) of them fell within two years. The correspondence between the two data sources is graphed in Figure 7. The correlation between NETS start dates and company website reported start dates was 0.87 . Our two checks, then, indicate that the NETS tracks establishment births quite accurately, adding to the overall evidence of the reliability of the NETS data.

\section{Employment Dynamics and Business Relocation in California}

\subsection{The policy debate over business relocation}

We illustrate the usefulness of the NETS data by addressing a substantive question regarding business establishment dynamics that figures prominently in policy debates, and for which the NETS database is uniquely suited. Specifically, business relocation is often cited as a source of job loss, especially at regional and state levels. While job loss due to business relocation is rarely precisely measured, it is often invoked in the rhetoric of policy debate and political campaigns. For example, when Kimberley-Clark moved its headquarters from Wisconsin to Texas in 1985, it sparked heavy criticism of Wisconsin's business climate, contributing to the governor losing his job in the following election (Dresang, 2002). Similarly, local governments work to attract companies to relocate to their jurisdictions (Klier and Testa, 2002). For example, in 2001, when Boeing announced that its headquarters would leave Seattle, cities like Chicago, Dallas, and Denver engaged in fierce competition to recruit the company. ${ }^{35}$

\footnotetext{
${ }^{34}$ Six of these 8 were founded in 2001 or 2002 . Hoovers.com (based on the same raw data from D\&B) listed a company record and DUNS number for all 6 of these records, indicating either that they were established too late to be included in our extract of the NETS database or that they were picked up by D\&B with a modest delay after their establishment.

${ }^{35}$ See, for example, http://www.conway.com/ssinsider/incentive/ti0106.htm (viewed on May 2, 2005).
} 
During the past decade, the debate over business relocation has been particularly prominent in policy discussions in California (see Neumark, et al., 2005b). The media, business leaders, and politicians pay close attention to incidents of businesses leaving California, often citing them as a threat to the state's economy, and as evidence of a hostile business climate. For example, during the gubernatorial recall election in 2003, the public was inundated with criticism of California's business environment and stories of businesses leaving California (e.g., Vames, 2003). Candidates for Governor routinely referred to the state's "onerous business regulations and over-taxation" (Roberts, 2003) that were believed to push businesses away. After Arnold Schwarzenegger won the recall election and became Governor, he adopted an aggressive public relations strategy focusing specifically on business relocation, which in turn led to a response from other states (Tamaki, 2004).

Claims regarding the importance of business relocation that have arisen in this debate, however, have rarely relied on empirical evidence of relocation behavior. Rather, they generally rely on surveys that elicit subjective assessments from employers (e.g., California Business Roundtable and Bain \& Company, 2004). One older study tried to measure actual relocation activity, based on data on manufacturing plants from the Los Angeles Department of Water and Power and several large utility companies in Southern California (Bules \& Associates, 1992). But this study - like most of the public debate - focused only on businesses leaving the state, as if traffic moves in only one direction.

Moreover, the debate is often framed as if relocation is the key determinant of employment change and hence a barometer of the "business climate." Yet the formation of new business establishments, the death of existing ones, and employment changes at continuing establishments, also affect employment change. Thus, the debate over business relocation ignores five of the six components of employment change (births, deaths, expansions, contractions, and in-migration), focusing only on the loss of jobs from establishments that move out of the state. The NETS data can obviously fill in many of the gaps in understanding the importance of business relocation (in both directions) in employment change, and more generally in identifying which processes - births, deaths, expansions, contractions, moves in, and moves out - drive employment change. 


\subsection{Aggregate-Level Evidence on Employment Dynamics}

This section presents our findings from the NETS data regarding business relocation in California and employment dynamics more generally. The analysis is at the aggregate state level. In the next section we consider some analyses, focused more exclusively on business relocation, at the industry level. In this section and the next, in each case we state our key result and then provide some detailed discussion.

1) California generally loses establishments and jobs due to business relocation, but the impact is negligible

As Table 4 shows, in every year during the 1992-2002 sample period, some establishments left California, taking jobs away; at the same time, others moved into California, bringing jobs to the state. Measured by either the number of business establishments or the number of jobs, California experienced a net loss owing to relocation in every year. However, compared with the size of its overall economy, California's net loss from relocation has to be considered negligible. In terms of number of establishments lost to other states, the worst years are 1993 and 1994. In each of these years, California lost about 750 establishments to other states, which amounted to $0.05 \%$ of the total number of establishments in California. The job numbers tell a similar story. In terms of job loss from relocation, 1994 and 1997 represent the worst years. In these years business relocation cost $0.1 \%$ of California jobs. Another way to see that these job change numbers are negligible is to compare them to ongoing employment changes that the state experiences. For example, from July 1990 to January 1993, employment in California fell by 6.1\%, while from December 1997 to December 2000, employment in California grew by $8.2 \%{ }^{36}$ These comparisons suggest that whether during an upturn or a downturn, business relocation simply does not play a major role in employment change.

\section{2) Establishments are much more likely to move locally than across state boundaries}

While establishment moves are quite common, most of these moves are within state. Out of 255,838 cases of establishment relocation originating in California during 1993-2002, 246,283 (or 96.3\%)

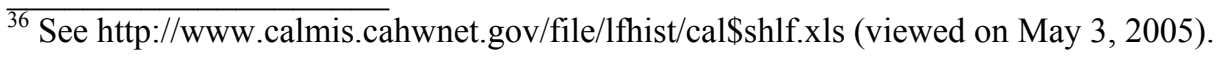


were moves within California. While cross-state moves draw a lot of attention, they are rare. In fact, $35.4 \%$ of all the moves originating in California occurred within a city and $78.5 \%$ of the moves did not go beyond the county boundary. ${ }^{37}$ As a result, the impact of relocation on employment on the local level, while still modest, is more pronounced than its effect on state employment. In 1993, though less than $0.01 \%$ establishments moved out of California, $0.4 \%$ of establishments moved outside their own county, and $1.2 \%$ of establishments moved beyond their own city. The employment changes associated with these moves represented $0.1 \%, 0.6 \%$, and $1.5 \%$ of total California employment, respectively. Of course, the preponderance of within-state moves may reflect the unique economic geography and size of California. The state has numerous quite different regional economies, and relatively few population centers near borders with other states that would permit "local" moves that nonetheless cross state lines.

3) Employment growth is primarily driven by expansion, contraction, births, and deaths

Table 5 presents decompositions of employment growth over three-year periods during 19922002. For each period, in the top panel we show California employment in the starting year, in the ending year, the overall net change, and then the number of jobs created or eliminated by each process of employment dynamics. The bottom panel shows the decomposition of employment change. In principle, we can decompose annual employment changes in the same way. But as noted earlier, year-to-year employment changes are not as reliable in the NETS data because of rounding and imputation.

Table 5 shows that in every three-year period the expansion of existing establishments always creates more jobs than are lost through the contraction of existing establishments. This is perhaps not surprising, because at any time we expect that the surviving business establishments tend to be those that are growing rather than shrinking. The net effects of births and deaths of establishments on overall employment change are positive in some years and negative in others. This tends to reflect the business cycle. In boom years many new establishments are created, and at the same time existing establishments are less likely to go out of business. As a result, jobs created by new establishments outnumber jobs eliminated by establishments that close in such years. Conversely, during slower economic times

\footnotetext{
${ }^{37}$ As discussed in the previous section, within-city moves may be undercounted in the NETS, in which case these percentages would be even higher.
} 
business formation is lower and more businesses tend to close, result in a net loss of jobs because new businesses do not suffice to cover the loss of those that die. For example, during 1995-1998, establishment deaths in California cut 454,000 jobs more than the number of jobs created through establishment births. But during the next three years, from 1998-2001, business establishment births and deaths resulted in a net gain of 848,000 new jobs.

The table also provides a comparison of the contribution of relocation to employment change with the contributions of other sources of employment change. The bottom rows of Table 5 indicate just how small the role of business relocation is. As the last row shows, the employment loss from relocation ranges from about 6,000 to 44,000, averaging around 20,000 per year. But the employment changes from the expansion-contraction processes and the birth-death processes are much greater, often by a factor of 20 or more. In other words, employment changes in California are primarily driven by expansioncontraction and birth-death processes, rather than by relocation.

The relative importance of different sources of employment change is illustrated more clearly in Figure 8. The two panels display the sources of job creation and destruction, respectively, in each threeyear period during 1992-2002. The top panel shows that in each period the birth of new business establishments is the major source of job creation, while the expansion of existing establishments is also important. The number of jobs created by business establishments that moved to California is trivial compared to the number of jobs created by the other two sources. Likewise, the bottom panel shows that the death of establishments is the major factor in job destruction. Contraction at existing establishments is also substantial but less important. Finally, business relocation out of California again contributes only minimally. But recall that, on net, it is expansion minus contraction that generally yields the largest share of employment growth, and is always positive.

The decomposition of the sources of employment change is informative about the potential for each of the underlying processes to lead to more dramatic variation in employment. Given that births and deaths contribute large gross flows into and out of employment, a quite modest change in the balance between births and deaths could lead to large shifts in net employment growth. In contrast, the very low 
gross job flows associated with relocation imply that even if the rate of mobility out of the state doubled, and establishments completely ceased to move into the state, there would be little impact on net employment change.

\section{4) Decompositions of the sources of employment change are sensitive to the interval over which the} change is measured, but regardless, the contribution of business establishment relocation is negligible

There is a potential caveat to the results reported in Table 5 and Figure 8. The magnitude of gross job creation and destruction, as well as its decomposition, is dependent on the interval length. First, as the interval gets shorter (for example, one year versus two, or a quarter versus a year), we might expect the gross flows to become larger because more employment changes due to temporary fluctuations are captured, although the opposite could occur (for example, as the interval length approaches zero).

Second, the longer the interval chosen, the greater the contribution of births and deaths to gross flows. To see this most simply, note that all establishments in existence during a period are born and die during that period as the period gets infinitely long. Recall that we concluded that the NETS was not as reliable when looking at employment changes over shorter time intervals. Nonetheless, Table 6 illustrates that changes in the interval length (from one to ten years) do not affect the relative ranking of the contribution of each process of employment change to either job creation or job destruction, nor do they change the conclusion that the contribution of relocation is minimal.

This issue is also relevant when we compare employment change decompositions to what we get from other data sets, although because other data sets do not have information on business relocation, we have not focused on such comparisons. Results from ES-202 data (for the earlier 1990-1994 period) are available at frequencies of one, two, and three years, for West Virginia (Spletzer, 2000). ${ }^{38}$ As shown in Table 7, for the ES-202 data for West Virginia about $40 \%$ of gross job creation is attributed to births, compared with nearly $60 \%$ in the NETS, and the corresponding numbers for the contribution of deaths to job destruction are $41 \%$ and $66 \%$. Part of the explanation for the smaller shares of job creation and destruction attributed to expansion and contraction in the NETS may stem from the "stickiness" in

\footnotetext{
$\overline{38}$ Published results from this source as well as the BED and LDB are only available on a quarterly basis for the United States as a whole, and that is a higher frequency than we can study with the NETS data.
} 
employment change, discussed earlier, resulting from rounding and imputation of employment in the NETS. Of course the data sources cover two very different states in periods with little overlap, which may also help account for the differences. Note, though, that as we extend the interval to two and to three years, the discrepancies between these two data sources lessen, although some differences remain. The better match as we move to the three-year interval is consistent with our earlier conclusions that employment change measures in the NETS become more accurate as the window lengthens.

\subsection{Industry-Level Evidence on Business Relocation}

We next consider three analyses of business relocation and employment dynamics at the industry level. There are at least three reasons to examine business relocation and other sources of employment change by industry. First, if employment change differs by industry, the composition of jobs can be shifting and this is masked by focusing exclusively on overall job changes. The quality of jobs may vary across industries along a number of dimensions. Most notable, perhaps, is variation in pay. Indeed, average earnings in different industries in California vary considerably. In 2000, average annual pay was about $\$ 60,000$ in finance, insurance, and real estate, and $\$ 58,000$ in manufacturing. In contrast, in retail average pay was only $\$ 22,000 .^{39}$ Thus, if a manufacturing job leaves the state and a retail job comes to the state, we might not want to view these as offsetting because, on average, a high-paying job has been replaced by a low-paying job.

Second, we would expect that business establishments in some industries are more mobile than in other industries; for example, we would expect that businesses that sell tradable goods may find it much easier to relocate to outside California but to maintain their customer base inside the state. In this case we may understate the importance of relocation when we look at the totals because we are averaging over industries where relocation is a viable strategy and industries where it is not.

Third, we have motivated the analysis of relocation in part based on attention to the issue on the part of the media, business leaders, and politicians. Although we have shown that relocation is a very minor contributor to job change, it is possible that relocation is important, and receives a good deal of

\footnotetext{
${ }^{39}$ This is partly because more workers in the retail sector work part-time, although clearly hourly pay is much lower in retail as well.
} 
attention, not because it constitutes a large flow of jobs but because it can reveal the "tip of the iceberg." That is, there may be a general problem with the health of industry $\mathrm{X}$ in California, but relocation behavior in the industry is most easily observable by the media and others. ${ }^{40}$ Thus, it is important to ask whether changes in each of the sources of net job growth by industry - expansions minus contractions, births minus deaths, and relocations - are positively correlated rather than uncorrelated.

To assess these questions, we examine business establishment dynamics and employment change by industry, as reported in Table 8 . We focus on one-digit SIC industries, although we break up the two largest industries - services and manufacturing - into sets of low-wage and high-wage two-digit subindustries, based on whether average annual pay (in 2000) was above or below average annual pay for the one-digit industry. ${ }^{41}$ We do this because, relative to other one-digit industries, manufacturing and services each include high-paying and low-paying sub-industries, ${ }^{42}$ implying that small employment changes in the one-digit industry could mask larger shifts from higher-paying to lower-paying jobs, or vice versa. For each industry, in the first four columns we show the total employment change over the period 1992-2002, and decompose the total change into three sources: expansions minus contractions, births minus deaths, and in-migration minus out-migration. ${ }^{43}$ The next four columns report the same figures on a percentage basis, showing the overall change in employment and the separate components as percentages of the 1992 total employment in the industry. Finally, the last column reports average annual pay (as of 2000) in each industry. Our findings are as follows:

\section{5) Job loss due to relocation has tended to occur in higher-paying industries}

We first consider the relationship between relocation and the quality of jobs as measured by annual average pay in the industry. This analysis focuses on the fourth and eighth columns of Table 8 ,

\footnotetext{
${ }^{40} \mathrm{We}$ are grateful to a referee for raising this issue.

${ }^{41} \mathrm{We}$ omit industry-specific results for mining, for agriculture, forestry, and fishing, and for government; the first two are small, and none of the three is generally subject to relocation as we normally think about it. These industries are, however, included in the first row of Table 8.

${ }^{42}$ This is reflected in far greater variance in average pay across two-digit industries within these one-digit industries, than in other one-digit industries.

${ }^{43}$ We also examined changes over shorter time intervals averaged over this decade, and the qualitative conclusions were the same.
} 
which show the levels of employment change due to relocation, and these changes as shares of 1992 employment, and the ninth column, which reports average pay.

There is evidence indicating that relocation cost more jobs in higher-paying than in lower-paying industries, suggesting that relocation may have had a negative impact - although modest - on the composition of jobs. In particular, net job loss attributable to relocation was highest in the finance, insurance, and real estate industry, where relocation cost nearly $2 \%$ of 1992 employment; and this is the highest-paying one-digit industry. Similarly, the contribution of relocation to job loss was higher in manufacturing - although the difference relative to other industries is much less pronounced - and manufacturing ranks second among one-digit industries in terms of average annual pay. Nonetheless, it is interesting that the job loss due to out-migration was the same in high-wage and low-wage manufacturing, indicating that there is not a tendency to lose the higher-wage jobs in this industry via relocation. Overall, though, the correlation between average annual pay and the net change in employment due to relocation is -0.23 , indicating that there was more job loss in industries where pay is high; using percentage changes in employment, the correlation is $-0.36 .^{44}$ This evidence implies that relocation - although it has a small influence - did tend to result in the substitution of lower-wage for higher-wage jobs over this period. 6) Job loss from interstate relocation is similar in "footloose" industries and other industries

Next, we look at differences in relocation by industry, with an emphasis on asking whether it is more significant in tradable-goods industries in which gross relocation rates are significantly higher. Table 8 shows that most private industries lost jobs due to relocation; the only exception is high-wage services. At the same time, as in the aggregate, the contribution of relocation to total employment change within industries is relatively small. In all industries except two, job loss due to business relocation over the decade is less than $1 \%$ of initial employment. (The comparable aggregate figure, shown in the first row of Table 8 , is $0.4 \%$.) Although California experienced a large loss in manufacturing jobs during

\footnotetext{
${ }^{44}$ The first measure is more meaningful as a simple description of the relationship between job change due to relocation and industry pay. These correlations are computed treating high-wage and low-wage manufacturing as two data points, and similarly for services. The computed correlations are much more negative if we do not disaggregate manufacturing and services into high- and low-wage sub-industries, which masks somewhat higher job loss from relocation in low-wage than in high-wage manufacturing, and job gains from relocation in high-wage services coupled with job loss in low-wage services.
} 
1992-2002 (as did many other states in the nation), job loss due to relocation in this industry is not a major contributor, accounting for a loss of $0.6 \%$ of jobs, versus $0.4 \%$ for all industries combined. Instead, business closures are far more important in explaining the decline in manufacturing jobs. Of course the NETS does not track moves overseas, which would be regarded as closures. From the perspective of simply accounting for job loss, the distinction may be irrelevant. But from the perspective of policy it is quite important. The finding that manufacturing job loss is not due to moves of manufacturing establishments to other states undermines arguments that the problem facing manufacturing in the state is a bad business climate relative to other states, although given the relatively small role of relocation we would learn more from comparisons across states of births, deaths, expansions, and contractions.

Moreover, the evidence indicates that relocation does not loom particularly larger in industries that are more "footloose." Although not reported in Table 8, we compared the distributions across industries of job changes due to in- and out-migration to the overall distribution of employment across industries. This calculation revealed that manufacturing (both high-wage and low-wage) is footloose. Its 1992 employment share was $15.1 \%$, but it contributed $32.1 \%$ of job gains due to in-migration, and $29.6 \%$ of job loss due to out-migration. In contrast, for example, retail trade had a 1992 employment share of $15.4 \%$, but contributed only $7.7 \%$ of in-migration and $5.3 \%$ of out-migration. However, while manufacturing is, as we would expect, more footloose, as already noted the net effect of relocation in manufacturing is still quite negligible, accounting for a loss of only $0.6 \%$ of jobs over $1992-2002$. Thus, relocation does not appear particularly more significant when we focus attention on the footloose manufacturing industry. Furthermore, the substantial job loss due to out-migration of business establishments in finance, insurance, and real estate is again worth noting because this is not a particularly footloose industry. In-migration is disproportionately low, contributing only $5.7 \%$ of the total job gains due to in-migration, relative to the industry's $7.3 \%$ share of 1992 employment. In contrast, this industry contributed $17.3 \%$ of total job loss attributable to out-migration. 


\section{7) Relocation does not appear to be an indicator of more substantial problems of job creation or}

destruction stemming from births, deaths, expansions, and contractions

Finally, we ask whether industries experiencing job loss due to relocation were also experiencing job loss due to either the excess of deaths over births, or of contractions over expansions. If so, one might argue that media and policy attention focused on relocations is detecting more widespread problems, and that perhaps the focus is on relocations because these are most easily observable. This could potentially be quite significant. We just noted that the correlation between job changes due to relocation and average industry pay is -0.23 . Relocation is small or negligible relative to job change from expansions, contractions, births, and deaths. But if there are similar correlations between net job change due to births minus deaths, or expansions minus contractions, and industry pay, this would indicate larger-scale substitution of jobs in low-paying industries for jobs in high-paying industries.

Some of the numbers in Table 8 suggest that this may not be the case. For example, job loss due to relocation is the same (as a share of 1992 employment) in high-wage and low-wage manufacturing, but job loss due to more deaths than births is much higher in low-wage manufacturing (19\% of 1992 employment, versus $6.4 \%$ for high-wage manufacturing). Similarly, although the job loss due to relocation is most pronounced in finance, insurance, and real estate, this industry also had robust net job creation due to expansions minus contractions, and a net job creation rate in about the middle of the pack due to births minus deaths. This overall impression is confirmed by looking at correlations across industries between the percentage changes in jobs due to each of the three net processes, which gauge whether trends in employment due to expansions minus contractions, births minus deaths, and relocations are similar or not. We find a correlation of -0.01 between the percentage changes in employment due to relocation and due to expansions minus contractions, 0.06 between the percentage changes due to relocation and due to births minus deaths, and 0.07 between the percentage changes due to relocation and 
the combination of births, deaths, expansions, and contractions. Thus, the patterns of job loss (or gain) in relocation are largely uncorrelated with the patterns generated by the other two net processes. ${ }^{45}$

\section{Conclusions}

We assess and present findings from a newly constructed longitudinal database covering business establishments - the National Establishment Time Series, or NETS. The NETS database is particularly well-suited to studying the underlying dynamics of employment change, specifically the processes of business establishment expansion and contraction, births and deaths, and relocations. As such, it builds on earlier research on this topic using the Longitudinal Research Database to study manufacturing, and numerous other data products based on the ES-202 data to study all sectors of the private economy. However, the NETS has some important advantages, including capturing business relocation, more complete coverage, and the ability to disaggregate to a fine geographic level, as well as ease of access and the absence of confidentiality restrictions.

Since the NETS is based on Dun \& Bradstreet data - which have been criticized in the past - we devote a great deal of attention to assessing the quality of the NETS. Overall, we conclude that the NETS data are quite reliable and in many respects comparable to more frequently used administrative and Census data. The NETS captures new businesses and start dates quite accurately. Coverage of business moves in the NETS is good, which enables researchers to tackle a source of job creation and destruction that has been understudied. One limitation is that because data are often initially imputed for new establishments, and there is considerable rounding of employment, short-term (such as one-year) employment changes are not measured very accurately; use of somewhat longer intervals mitigates this problem.

\footnotetext{
$\overline{{ }^{45}}$ The correlations of the absolute (rather than percentage) changes are more positive, but these are driven by variation in the size of industries, and are less reflective of how similar relocation trends are to trends in births minus deaths, expansions minus contractions, or their combination. Furthermore, the larger positive correlation between employment change due to relocation and due to the other dynamic processes is in large part driven by high-wage services, which is the one (sub)-industry that experienced employment growth due to relocation and also experienced relatively large employment increases due to the other dynamic processes (especially births minus deaths).
} 
Partly as an illustration of the value of the NETS data, and partly out of substantive interest, we use the data to study employment dynamics in California. We provide overall decompositions of the sources of employment change in the state, focusing particular attention on the empirical importance of business relocation into and out of the state, which has figured prominently in policy discussions.

We find that the birth-death and expansion-contraction processes of business establishments are responsible for nearly all gross job creation and destruction and that cross-state business relocation is virtually a negligible factor. Cross-state business relocation resulted in a net job loss to California in every year during the period 1993-2002. However, compared to the size of the California economy, the net loss from relocation is trivial. This limited effect of business relocation on employment is also found within each industry, although business establishments in certain industries (such as manufacturing) are much more likely to move in both directions. There is some evidence that relocation - though relatively unimportant empirically - has cost the state higher-paying jobs. Finally, trends in job loss from relocation do not appear to be indicative of related trends in job loss from the other dynamic processes driving employment. Overall, given the small role played by relocation in job growth, these findings imply that a policy focus on business relocation is badly misdirected, and unlikely - even if successful at attracting new businesses and retaining old ones - to contribute visibly to job growth. To the extent that policy has any role to play, the evidence suggests that efforts to foster the formation of new businesses and to help existing businesses survive and grow would be better placed, unless relocation behavior is inordinately responsive to policy. 


\section{References}

Aldrich, Howard, Arne Kalleberg, Peter Marsden, and James Cassell, "In Pursuit of Evidence: Sampling Procedures for Locating New Businesses," Journal of Business Venturing 4, 1989, 367-386.

Allaman, Peter M and David L. Birch, "Components of Employment Change for States by Industry Group, 1970-1972,” Working Paper No. 5, Joint Center for Urban Studies of MIT and Harvard University, 1975.

Audretsch, David B., Innovation and Industry Evolution, The MIT Press, Cambridge, 1995.

Baldwin, John and Garnett Picot, "Employment Generation by Small Producers in the Canadian Manufacturing Sector,” Small Business Economics 7, 1995, 317-331.

Bednarzik, Robert W., "The Role of Entrepreneurship in U.S. and European Job Growth," Monthly Labor Review 123, 2000, pp. 3-16.

Benedetto, Gary, John Haltiwanger, Julia Lane, and Kevin McKinney, "Using Worker Flows to Measure Firm Dynamics," unpublished manuscript, University of Maryland, 2004.

Birch, David L., "The Job Generation Process," unpublished report prepared by the MIT Program on Neighborhood and Regional Change for the Economic Development Administration, U.S.

Department of Commerce, Washington, D.C., 1979.

Birch, David L., "Who Creates Jobs?” The Public Interest 65, 1981, 3-14.

Birch, David L., Job Creation in America: How Our Smallest Companies Put the Most People to Work, Free Press, New York, 1987.

Birley, Sue, "Finding the New Firms," Proceedings of the Academy of Management Meetings 47, 1984, 64-68.

Broersma, Lourens and Pieter Gautier, "Job Creation and Job Destruction by Small Firms: An Empirical Investigation for the Dutch Manufacturing Sector," Small Business Economics 9, 1997, 21 1-224.

Bules \& Associates, "California Industry Migration Study," prepared for Los Angeles Department of Water and Power, PG\&E, Sand Diego Gas and Electric Company, Southern California Edison Company, and Southern California Gas Company, San Francisco, California, October 1992.

California Business Roundtable and Bain \& Company, "California Competitiveness Project," February 2004.

Davidsson, Per, Leif Lindmark, and Christer Olofsson, "The Extent of Overestimation of Small Firm Job Creation - An Empirical Analysis of the Regression Bias," Small Business Economics 11, 1998, 87100.

Davis, Steven J., and John Haltiwanger, "Gross Job Creation, Gross Job Destruction, and Employment Reallocation," Quarterly Journal of Economics 107, 1992, 819-863.

Davis, Steven J., John C. Haltiwanger, and Scott Schuh, Job Creation and Destruction, The MIT Press, Cambridge, MA, 1996.

Dresang, Joel, "Firm's Relocation Unseated a Governor," in Milwaukee Journal Sentinel on October 13, 2002, available online at http://www.jsonline.com/bym/news/oct02/87385.asp (viewed June 1, 2005).

Dunne, Timothy, Shawn Klimek, and Mark J. Roberts, "Entry and Exit in Geographic Markets," unpublished manuscript, University of Oklahoma, 2005.

Dunne, Timothy, Mark Roberts, and Larry Samuelson, "Plant Turnover and Gross Employment Flows in the U.S. Manufacturing sector," Journal of Labor Economics 7, 1989a, 48-71. 
Dunne, Timothy, Mark Roberts, and Larry Samuelson, "The Growth and Failures of U.S. Manufacturing Plants," Quarterly Journal of Economics 104, 1989b, 671-698.

Foster, Lucia, "The Appalachian Economy, Establishment and Employment Dynamics, 1982-1997: Evidence from the Longitudinal Business Database," unpublished manuscript, Center for Economic Studies, U.S. Bureau of the Census, 2003.

Jarmin, Ronald S., Shawn D. Klimek, and Javier Miranda, “The Evolution of Retail Markets in Metropolitan, Micropolitan and Rural Regions," unpublished manuscript, Center for Economic Studies, U.S. Census Bureau, 2005.

Jarmin, Ron S., and Javier Miranda, "The Longitudinal Business Database," unpublished manuscript, Center for Economic Studies, U.S. Census Bureau, Suitland, Maryland, 2002.

Klier, Thomas and William Testa, "Location Trends of Large Company Headquarters during the 1990s," Economic Perspectives, Federal Reserve Bank of Chicago, 2002, 12-26.

Leonard, Jonathan S., "In the Wrong Places at the Wrong Time: The Extent of Frictional and Structural Unemployment," in Kevin Lang and Jonathan S. Leonard (eds.), Unemployment and the Structure of Labor Markets, Blackwell, New York, 1987, 141-163.

MacDonald, James M., "Dun \& Bradstreet Business Microdata: Research Applications, and the Detection and Correction of Errors," Journal of Economic and Social Measurement 13, 1985, 173-185.

Neumark, David, Junfu Zhang, and Brandon Wall. "Employment Dynamics and Business Relocation: New Evidence from the National Establishment Time Series," NBER Working Paper 11647, $2005 \mathrm{a}$.

Neumark, David, Junfu Zhang, and Brandon Wall. "Are Businesses Fleeing the State? Interstate Business Relocation and Employment Change in California," California Economic Policy 1(4), 2005b.

Roberts, Timothy, “Execs’ Ad to Politicos: Enough,” Silicon Valley / San Jose Business Journal, September 26, 2003.

Schumpeter, Joseph A., Capitalism, Socialism, and Democracy, Harper \& Row, New York, 1942.

Spletzer, James R., "The Contribution of Establishment Births and Deaths to Employment Growth," Journal of Business and Economic Statistics 18, 2000, 113-126.

Tamaki, Julie, "Battle of the State Billboards," Los Angeles Times, October 11, 2004.

U.S. Bureau of Labor Statistics, BLS Handbook of Methods, Department of Labor, 1997, available online at http://www.bls.gov/opub/hom/home.htm (viewed on March 2, 2006).

U.S. Census Bureau, "The Longitudinal Employer-Household Dynamics Program: Employment Dynamics Estimates Project Versions 2.2 and 2.3," Suitland, MD, 2002.

Vames, Steven, “Businesses Ponder Leaving California: For Some Firms, California Isn't Golden State Anymore," The Wall Street Journal Online.

van Dijk, Jouke, and Piet H. Pellenbarg, "Firm Relocation Decisions in The Netherlands: An Ordered Logit Approach," Papers in Regional Science 79, 2000, pp. 191-219.

Walls \& Associates, "NETS: National Establishment Time-Series Database," Oakland, California, 2003. 
Figure 1: NETS and QCEW Employment by County and Industry (1997-2000)

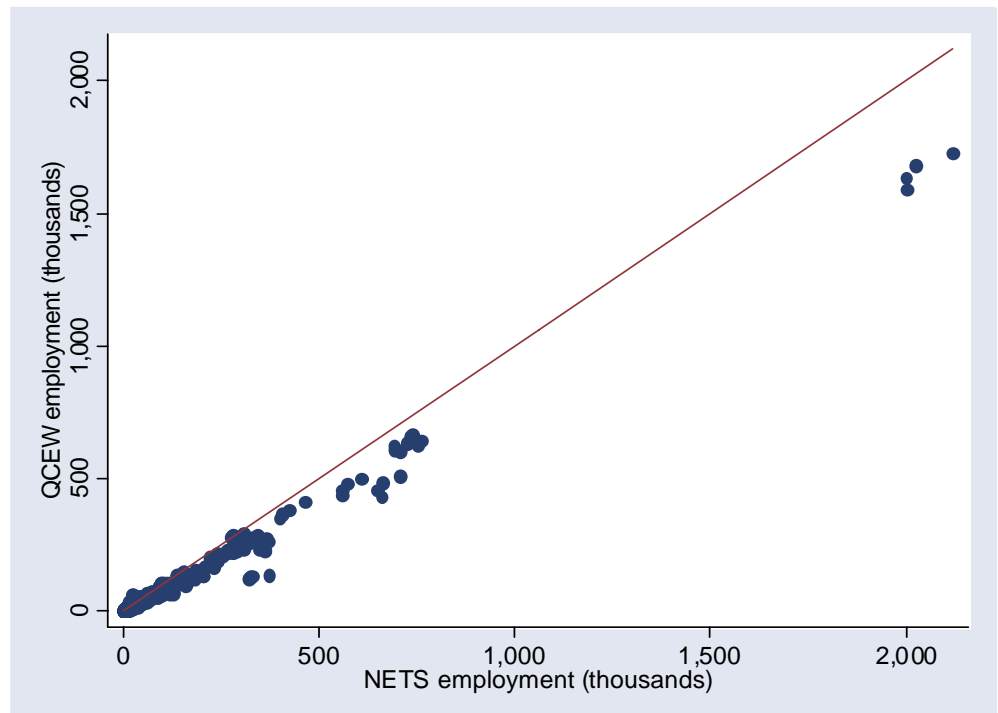

Figure 2: NETS and SOB Employment by Size Category (2002), Subtracting One Employee from Each NETS Establishment, and Reassigning to New Establishment Size Categories

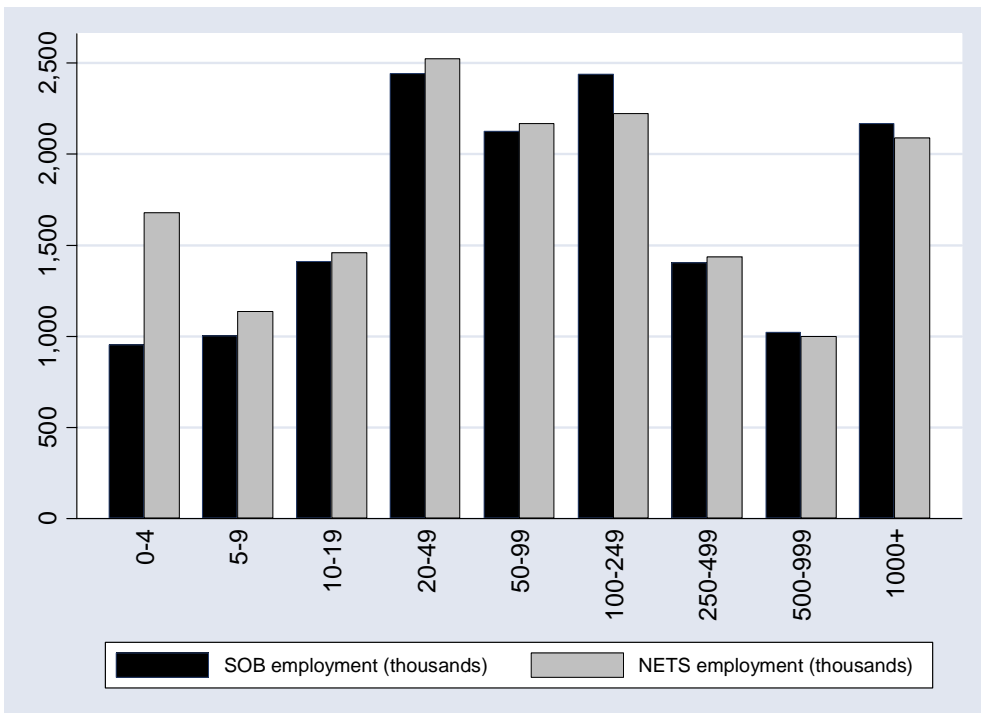


Figure 3: Histogram of NETS Establishment Sizes, 10-100 Employees (2000)

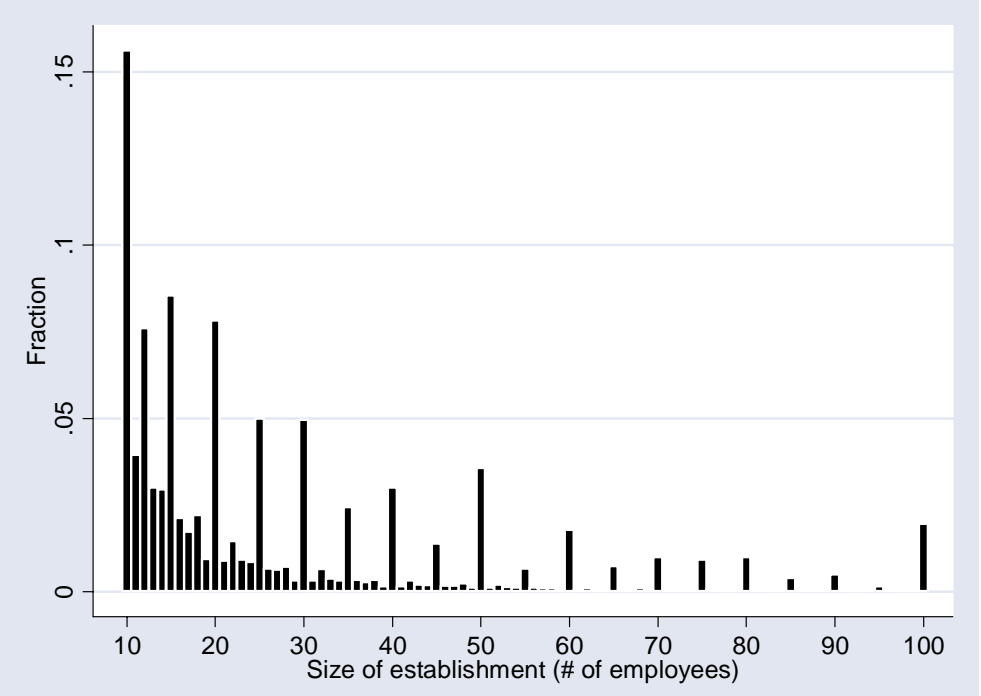

Figure 4: Histogram of NETS Establishment Sizes, 101-500 Employees (2000)

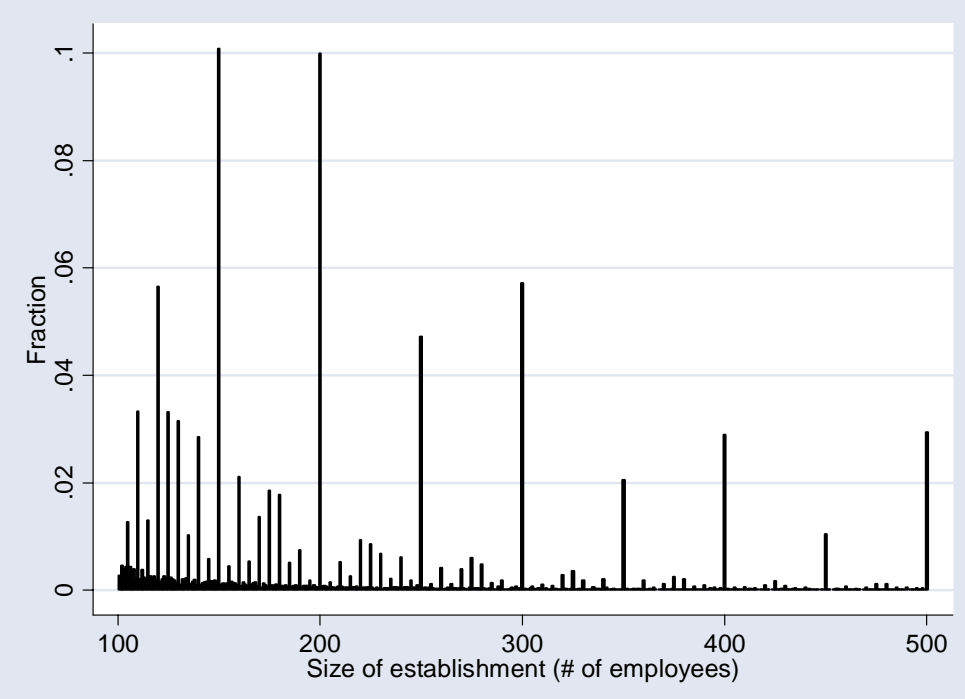


Figure 5: QCEW/NETS Employment Changes, by Industry and County, One-Year Changes (1997-1998, 1998-1999, 1999-2000)

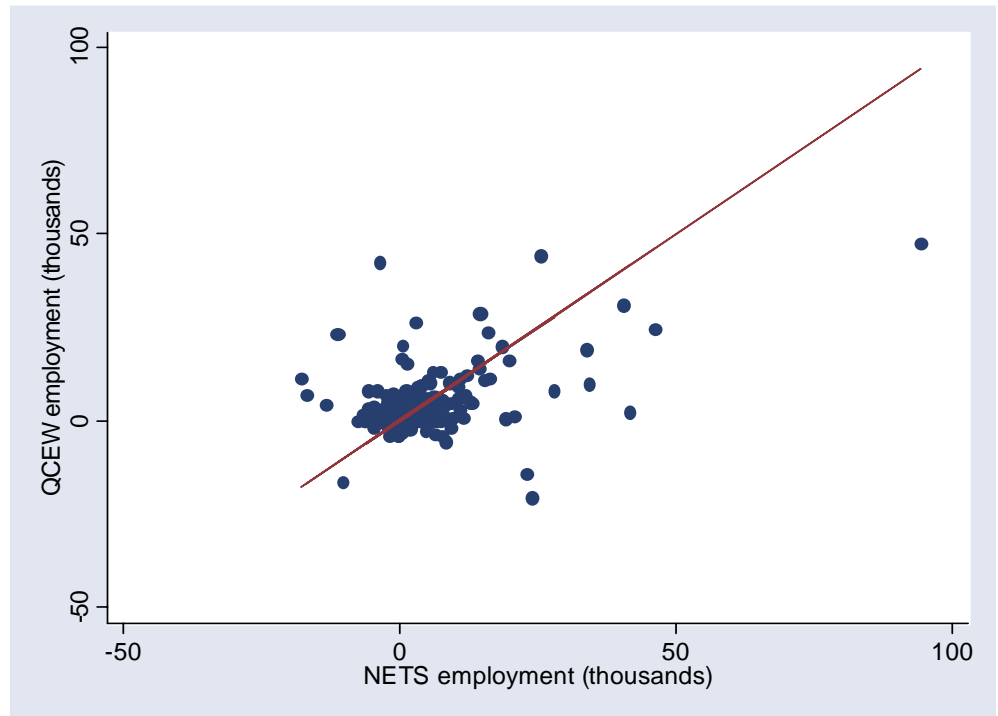

Figure 6: QCEW/NETS Employment Changes, by Industry and County, Three-Year Changes (1997-2000)

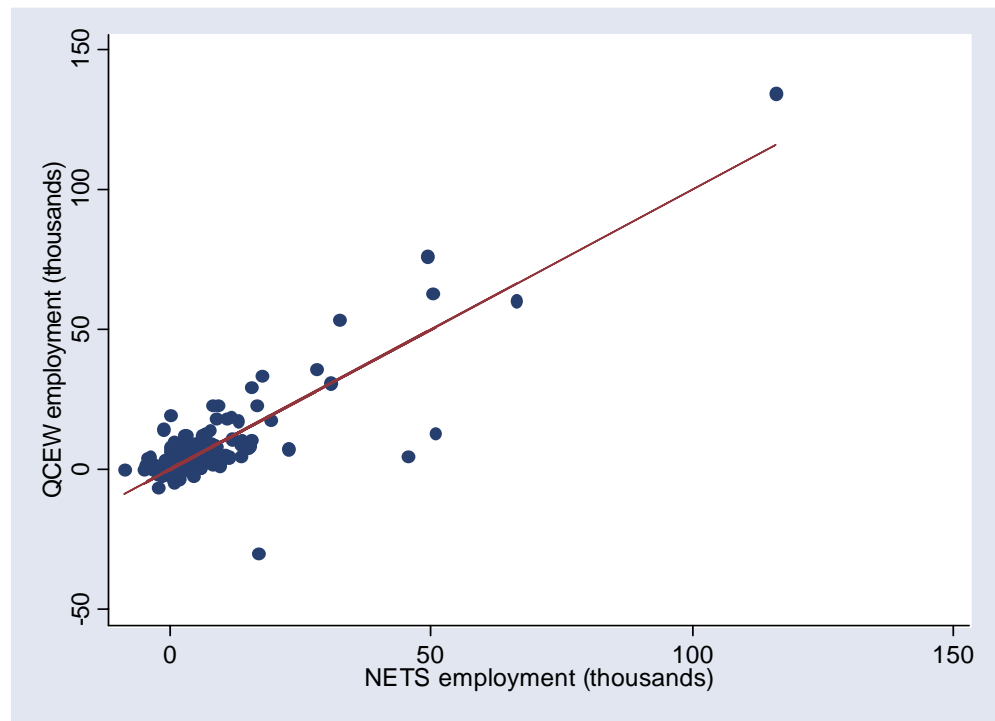


Figure 6: Establishment Openings by Year, Company-Reported vs. NETS-Reported

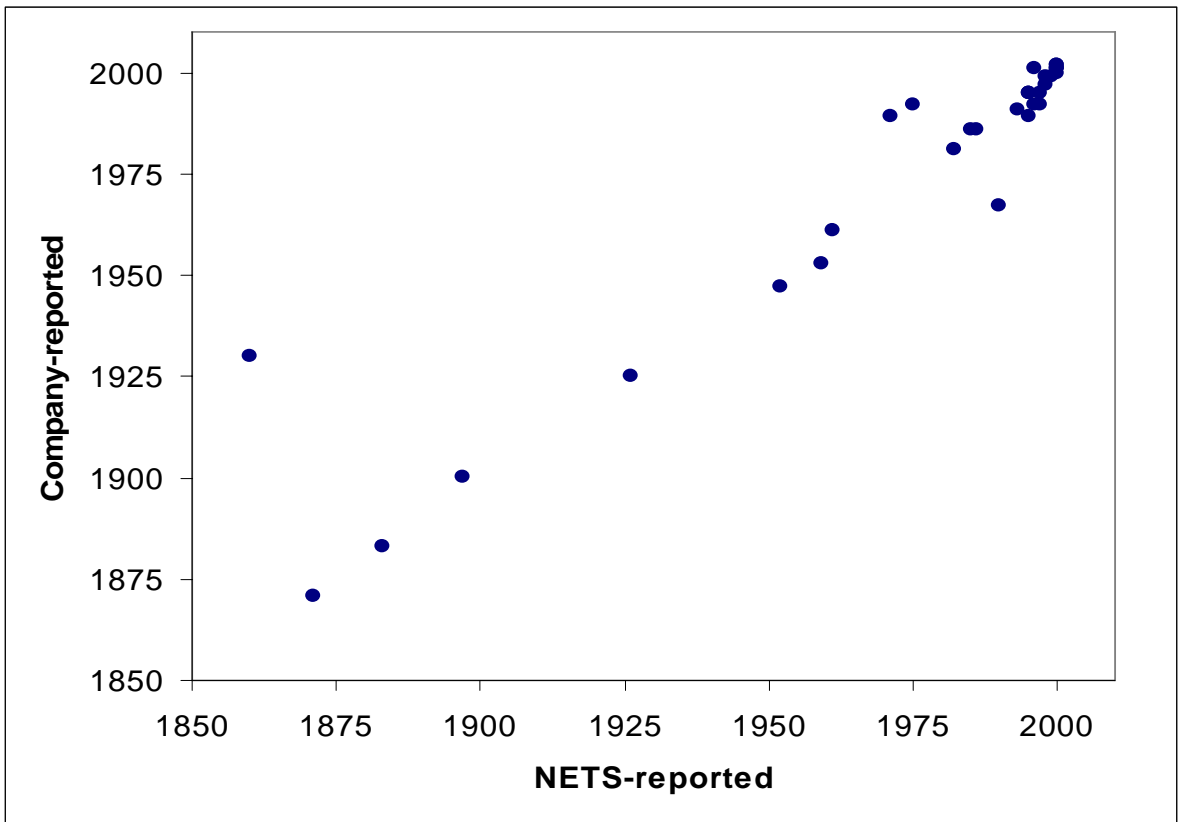

Figure covers establishments identified as opening in 2001 or 2002 from phonebooks, and identified in the NETS.

Figure 7: Biotech Establishment Openings by Year, Reported on Company Website vs. NETSReported

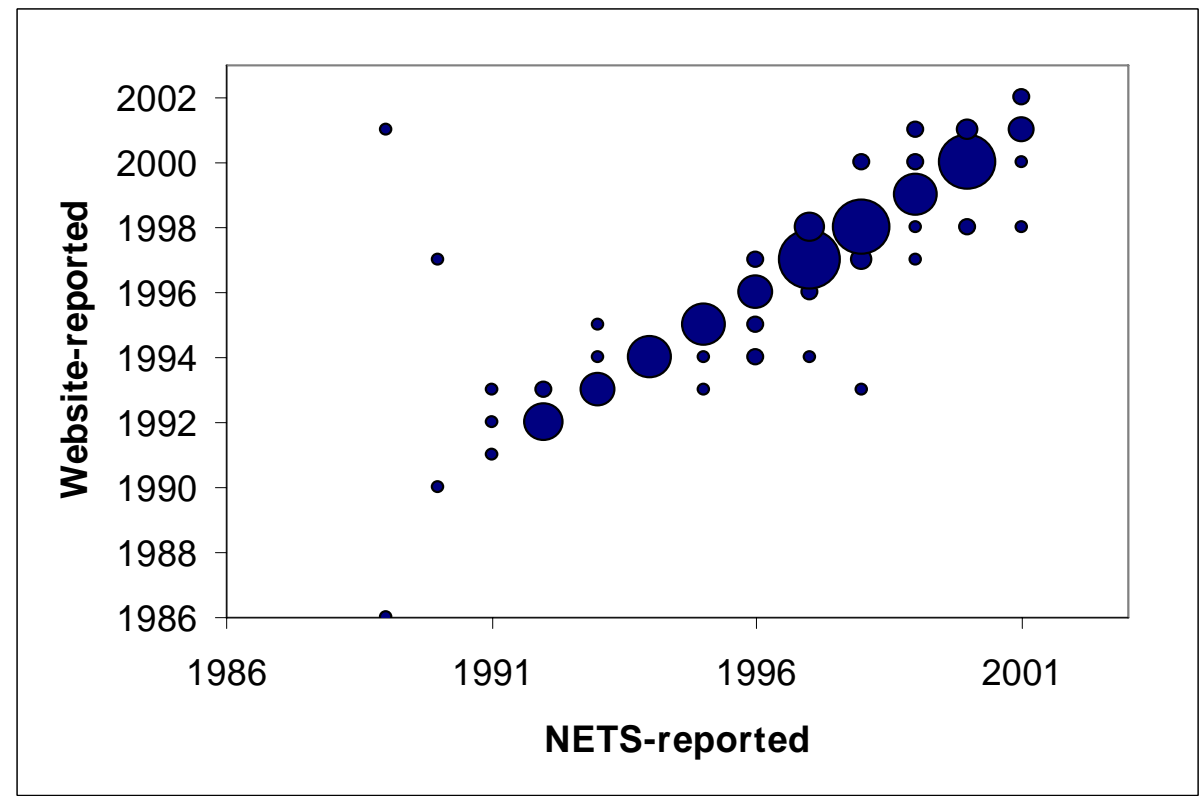

Areas of symbols are proportional to the number of observations with the same dates in both data sources. 
Figure 8: Job Creation and Destruction

(a) Sources of Job Creation

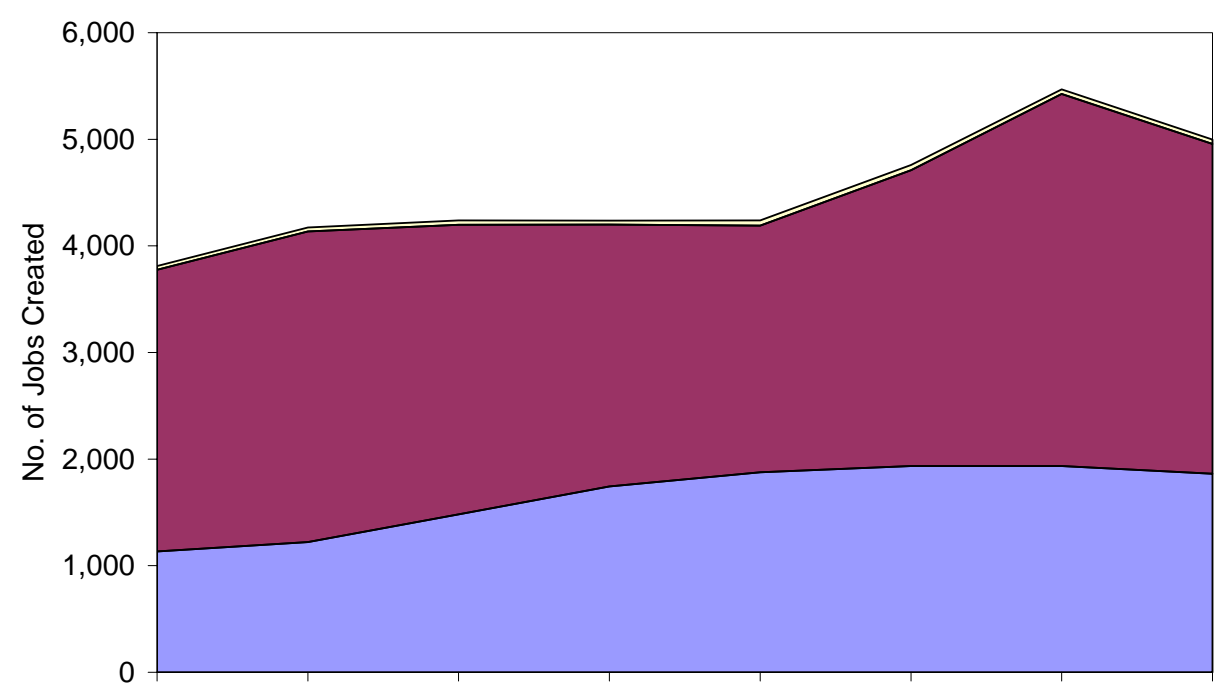

1992-1995 1993-1996 1994-1997 1995-1998 1996-1999 1997-2000 1998-2001 1999-2002

$\square$ Expansion $\square$ Birth $\square$ Move in

(b) Sources of Job Destruction

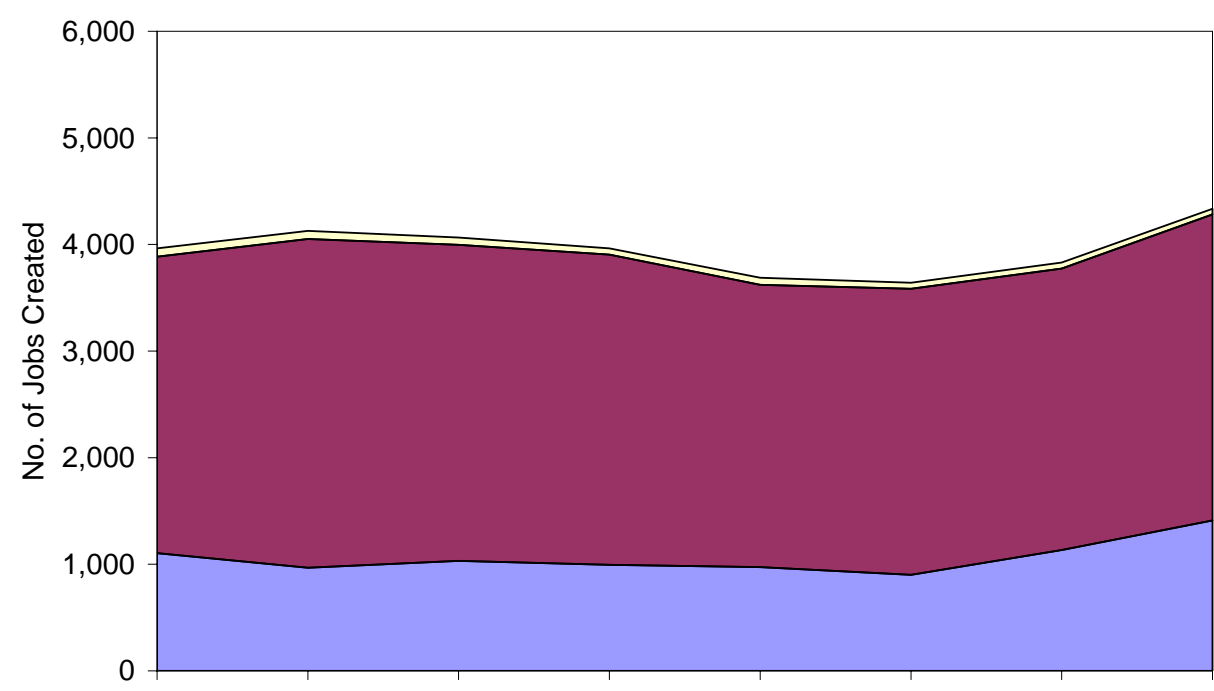

1992-1995 1993-1996 1994-1997 1995-1998 1996-1999 1997-2000 1998-2001 1999-2002 $\square$ Contraction $\square$ Death $\square$ Move out

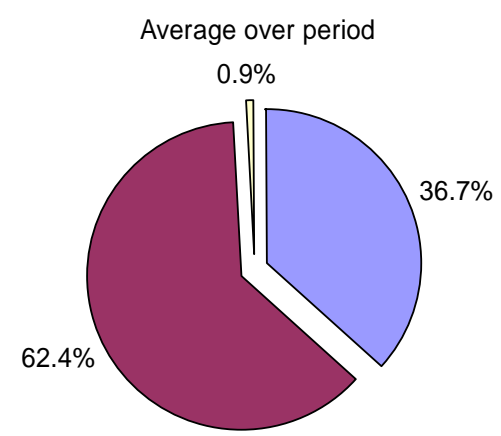

Average over period $1.6 \%$

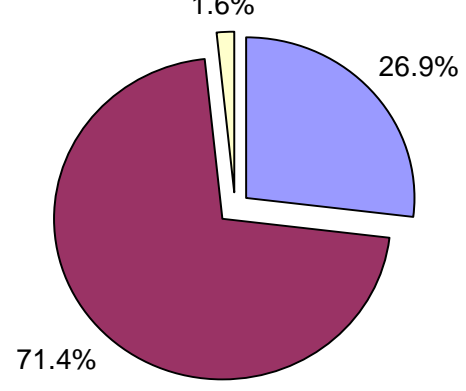


Table 1: Previous Data Sources for Studying Employment Dynamics in the United States

\begin{tabular}{|c|c|c|}
\hline Database & Description & Evaluations and applications \\
\hline Early D\&B data & $\begin{array}{l}\text { Annual establishment-level data collected by } \\
\text { the credit rating company Dun \& Bradstreet } \\
\text { for their commercial uses. }\end{array}$ & $\begin{array}{l}\text { Birch }(1979,1981 \text {, and 1987) uses the data to study the } \\
\text { role of small firms in job creation. Allaman and Birch } \\
\text { (1975) study geographic migration of businesses. } \\
\text { Aldrich, et al. (1989) show that the D\&B data used by } \\
\text { Birch tracked new businesses poorly. Davis, et al. (1996) } \\
\text { noted that the D\&B data overstate total employment than } \\
\text { BLS or the Census. }\end{array}$ \\
\hline $\begin{array}{l}\text { U. S. Establishment and } \\
\text { Enterprise Microdata } \\
\text { (USEEM) }\end{array}$ & $\begin{array}{l}\text { The U.S. Small Business Administration used } \\
\text { the D\&B data from the late 1970s and early } \\
\text { 1980s to create this data file, which linked } \\
\text { establishments cross-sectionally (with parent } \\
\text { firms) and over time. }\end{array}$ & $\begin{array}{l}\text { Research assessing this file points to some coding and } \\
\text { related errors common to most data sets, problems with } \\
\text { coverage of single owner-operator establishments in a } \\
\text { few sectors, and overall higher counts of employment in } \\
\text { small establishments compared to Census data. Overall, } \\
\text { though, the research concludes that the coverage of the } \\
\text { file was quite accurate and timely (MacDonald, 1985, p. } \\
\text { 180). Audretsch (1995) provides some further analysis of } \\
\text { the quality of the USEEM and uses the data to study } \\
\text { industry evolution. }\end{array}$ \\
\hline $\begin{array}{l}\text { Census of Manufactures } \\
\text { (CM) }\end{array}$ & $\begin{array}{l}\text { The Census of Manufactures is one part of the } \\
\text { Economic Census collected by the U.S. } \\
\text { Census Bureau every five years. It is } \\
\text { restricted to the manufacturing sector and } \\
\text { covers establishments with five or more } \\
\text { employees. }\end{array}$ & $\begin{array}{l}\text { Dunne, et al. (1989a, 1989b) use these data to study } \\
\text { manufacturing plant turnover, growth, and their resulting } \\
\text { employment flows. }\end{array}$ \\
\hline $\begin{array}{l}\text { Longitudinal Research } \\
\text { Database (LRD) }\end{array}$ & $\begin{array}{l}\text { Created by the Census Bureau, the LRD is a } \\
\text { large micro database of establishment-level } \\
\text { data constructed by combining information } \\
\text { from the Census of Manufactures (CM) and } \\
\text { the Annual Survey of Manufactures (ASM). It } \\
\text { is restricted to the manufacturing sector and } \\
\text { covers establishments with five or more } \\
\text { employees. }\end{array}$ & $\begin{array}{l}\text { A large amount of literature has been based on LRD. See, } \\
\text { for example, Davis and Haltiwanger (1992) and Davis, et } \\
\text { al. (1996), which use the LRD data to study the process } \\
\text { of job creation, job destruction, and employment } \\
\text { reallocation. }\end{array}$ \\
\hline $\begin{array}{l}\text { Longitudinal Business } \\
\text { Database (LBD) }\end{array}$ & $\begin{array}{l}\text { The LBD is created by the Census Bureau. It } \\
\text { covers almost all the non-farm private } \\
\text { economy, as well as some public sector } \\
\text { activities, improving upon the coverage of } \\
\text { LRD. }\end{array}$ & $\begin{array}{l}\text { Jarmin and Miranda (2002) documents the efforts of } \\
\text { constructing LBD at the Census Bureau. Foster (2003) } \\
\text { uses LBD data to study establishment and employment } \\
\text { dynamics in Appalachia. Recent studies using the LBD } \\
\text { are Jarmin, et al. (2005), and Dunne, et al. (2005). }\end{array}$ \\
\hline $\begin{array}{l}\text { Longitudinal Employer- } \\
\text { Household Dynamics } \\
\text { (LEHD) data }\end{array}$ & $\begin{array}{l}\text { Also based in the Census Bureau, the LEHD } \\
\text { program links federal and state administrative } \\
\text { data with the Bureau's censuses and surveys } \\
\text { to create a longitudinal database of employers } \\
\text { and their employees. }\end{array}$ & $\begin{array}{l}\text { U.S. Census Bureau (2002) provides detailed } \\
\text { documentation of the LEHD data. Benedetto, et al. } \\
\text { (2004) explore exploiting the LEHD to improve tracking } \\
\text { of entry and exit of firms as well as administrative } \\
\text { changes by following clusters of matched workers. }\end{array}$ \\
\hline $\begin{array}{l}\text { Unemployment } \\
\text { Insurance (UI) data }\end{array}$ & $\begin{array}{l}\text { State employment security agencies are } \\
\text { authorized by law to collect employment and } \\
\text { wage information on workers covered by } \\
\text { unemployment insurance, which result in a } \\
\text { large amount of data on both employers and } \\
\text { employees. UI data cover employers in all } \\
\text { sectors and all size categories (except no } \\
\text { employees), but do not capture physical } \\
\text { relocations of business establishments. }\end{array}$ & $\begin{array}{l}\text { Leonard (1987) uses UI data to describe the nature and } \\
\text { magnitude of structural and frictional shifts in } \\
\text { employment across industries and establishments. } \\
\text { Spletzer (2000) uses UI data from West Virginia to study } \\
\text { the contribution of establishment births and deaths to } \\
\text { employment growth. }\end{array}$ \\
\hline
\end{tabular}


Table 2: Accounting for the Discrepancies between NETS and SOB Employment (1994-2002)

\begin{tabular}{|c|c|c|c|c|c|c|c|c|c|}
\hline & 1994 & 1995 & 1996 & 1997 & 1998 & 1999 & 2000 & 2001 & 2002 \\
\hline 1. NETS & $16,371,012$ & $16,241,156$ & $16,314,659$ & $16,546,553$ & $16,512,479$ & $16,864,781$ & $17,666,262$ & $18,149,748$ & $17,527,918$ \\
\hline 2. Size of Business $(\mathrm{SOB})^{1}$ & $12,696,157$ & $13,047,314$ & $13,312,913$ & $13,739,592$ & $14,257,229$ & $14,642,495$ & $15,144,896$ & $14,997,165$ & $14,967,297$ \\
\hline $\begin{array}{l}\text { 3. Self-employed / } \\
\text { independent contractor } \\
(\mathrm{SE} / \mathrm{IC})^{2}\end{array}$ & $2,084,696$ & $2,093,767$ & $2,008,958$ & $2,083,693$ & $1,851,667$ & $1,893,306$ & $1,877,283$ & $1,899,806$ & $1,895,814$ \\
\hline $\begin{array}{l}\text { 4. Size of Business }+ \text { self- } \\
\text { employed / independent } \\
\text { contractor }(\mathrm{SOB}+\mathrm{SE} / \mathrm{IC})\end{array}$ & $14,780,853$ & $15,141,081$ & $15,321,871$ & $15,823,285$ & $16,108,896$ & $16,535,801$ & $17,022,179$ & $16,896,971$ & $16,863,111$ \\
\hline $\begin{array}{l}\text { 5. Current Population Survey } \\
\text { (CPS) }\end{array}$ & $13,979,022$ & $14,039,848$ & $14,261,005$ & $14,791,531$ & $15,180,850$ & $15,522,223$ & $16,056,438$ & $16,249,075$ & $16,214,933$ \\
\hline 6. Row $1-$ row 4 & $1,590,159$ & $1,100,075$ & 992,788 & 723,268 & 403,583 & 328,980 & 644,083 & $1,252,777$ & 664,807 \\
\hline 7. Row $5-$ row 4 & $-801,831$ & $-1,101,233$ & $-1,060,866$ & $-1,031,754$ & $-928,046$ & $-1,013,578$ & $-965,741$ & $-647,896$ & $-648,178$ \\
\hline
\end{tabular}

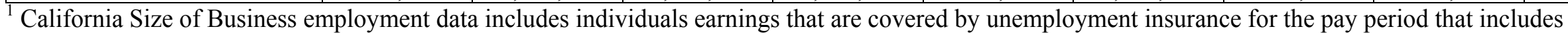

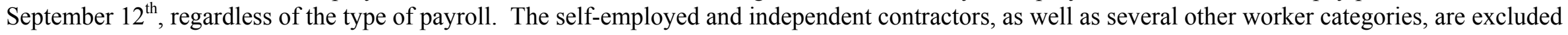
from unemployment insurance coverage (California Unemployment Insurance Code, Chapter 3, Article 2, Section 656).

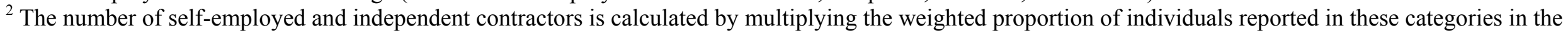

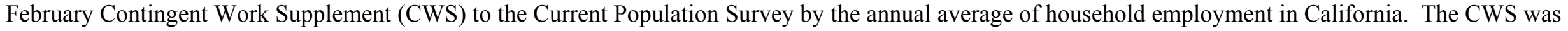

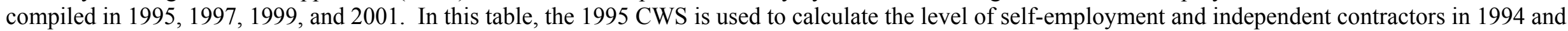
1995; the 1997 CWS is used for 1996 and 1997; the 1999 CWS is used for 1998 and 1999; and the 2001 CWS is used for 2000,2001 , and 2002. 
Table 3: Share with Employment Changes from Previous Year, by Employment Imputation Type (1993-2002)

\begin{tabular}{|l|ccc|}
\hline & Actual Figure & D\&B Estimate & Walls Estimate \\
\hline 1993 & $11.74 \%$ & $0.02 \%$ & $1.62 \%$ \\
1994 & $8.01 \%$ & $0.02 \%$ & $2.00 \%$ \\
1995 & $11.23 \%$ & $0.02 \%$ & $2.56 \%$ \\
1996 & $13.05 \%$ & $0.02 \%$ & $3.17 \%$ \\
1997 & $12.23 \%$ & $0.01 \%$ & $4.30 \%$ \\
1998 & $11.85 \%$ & $0.00 \%$ & $4.65 \%$ \\
1999 & $11.56 \%$ & $0.01 \%$ & $4.56 \%$ \\
2000 & $8.24 \%$ & $0.01 \%$ & $2.82 \%$ \\
2001 & $9.29 \%$ & $5.74 \%$ & $9.41 \%$ \\
2002 & $8.36 \%$ & $29.14 \%$ & $0.01 \%$ \\
\hline
\end{tabular}

Table 4: Business Relocation and Its Effect on Employment in California, 1992-2002

\begin{tabular}{|c|c|c|c|c|c|}
\hline \multicolumn{6}{|c|}{ A. By number of establishments } \\
\hline & Moved in & Moved out & Net effect & $\begin{array}{l}\text { Total number of } \\
\text { establishments }\end{array}$ & $\begin{array}{c}\text { Net loss as } \% \\
\text { of total }\end{array}$ \\
\hline 1993 & 612 & 1,364 & -752 & $1,532,256$ & $0.049 \%$ \\
\hline 1994 & 534 & 1,285 & -751 & $1,515,142$ & $0.050 \%$ \\
\hline 1995 & 519 & 1,104 & -585 & $1,497,623$ & $0.039 \%$ \\
\hline 1996 & 489 & 835 & -346 & $1,521,247$ & $0.023 \%$ \\
\hline 1997 & 504 & 763 & -259 & $1,518,940$ & $0.017 \%$ \\
\hline 1998 & 545 & 676 & -131 & $1,492,105$ & $0.009 \%$ \\
\hline 1999 & 582 & 669 & -87 & $1,461,135$ & $0.006 \%$ \\
\hline 2000 & 802 & 828 & -26 & $1,519,325$ & $0.002 \%$ \\
\hline 2001 & 752 & 1,032 & -280 & $1,644,230$ & $0.017 \%$ \\
\hline 2002 & 731 & 999 & -268 & $1,814,938$ & $0.015 \%$ \\
\hline \multicolumn{6}{|c|}{ B. By number of jobs } \\
\hline Year & Moved in & Moved out & Net effect & $\begin{array}{c}\text { Total number of } \\
\text { jobs }\end{array}$ & $\begin{array}{c}\text { Net loss as } \% \\
\text { of total }\end{array}$ \\
\hline 1993 & 13,853 & 27,094 & $-13,241$ & $16,266,713$ & $0.081 \%$ \\
\hline 1994 & 8,977 & 25,452 & $-16,475$ & $16,371,012$ & $0.101 \%$ \\
\hline 1995 & 14,136 & 28,224 & $-14,088$ & $16,241,156$ & $0.087 \%$ \\
\hline 1996 & 13,158 & 18,352 & $-5,194$ & $16,314,659$ & $0.032 \%$ \\
\hline 1997 & 11,073 & 28,209 & $-17,136$ & $16,546,553$ & $0.104 \%$ \\
\hline 1998 & 15,098 & 16,709 & $-1,611$ & $16,512,479$ & $0.010 \%$ \\
\hline 1999 & 18,893 & 23,437 & $-4,544$ & $16,864,781$ & $0.027 \%$ \\
\hline 2000 & 15,589 & 16,994 & $-1,405$ & $17,666,262$ & $0.008 \%$ \\
\hline 2001 & 18,586 & 23,916 & $-5,330$ & $18,149,748$ & $0.029 \%$ \\
\hline 2002 & 12,656 & 16,551 & $-3,895$ & $17,527,918$ & $0.022 \%$ \\
\hline
\end{tabular}


Table 5: Decomposition of Employment Growth in California

\begin{tabular}{|c|c|c|c|c|c|c|c|c|}
\hline & $1992-1995$ & 1993-1996 & 1994-1997 & $1995-1998$ & 1996-1999 & $1997-2000$ & 1998-2001 & 1999-2002 \\
\hline \multicolumn{9}{|l|}{ A. Employment change } \\
\hline Starting employment & $16,394,151$ & $16,266,713$ & $16,371,012$ & $16,241,156$ & $16,314,659$ & $16,546,553$ & $16,512,479$ & $16,864,781$ \\
\hline Ending employment & $16,241,156$ & $16,314,659$ & $16,546,553$ & $16,512,479$ & $16,864,781$ & $17,666,262$ & $18,149,748$ & $17,527,918$ \\
\hline Change & $-152,995$ & 47,946 & 175,541 & 271,323 & 550,122 & $1,119,709$ & $1,637,269$ & 663,137 \\
\hline \multicolumn{9}{|l|}{ Job creation: } \\
\hline Expansion & $1,134,603$ & $1,220,681$ & $1,480,284$ & $1,742,557$ & $1,874,193$ & $1,933,519$ & $1,934,525$ & $1,862,952$ \\
\hline Birth & $2,641,169$ & $2,915,369$ & $2,716,969$ & $2,456,024$ & $2,317,230$ & $2,776,719$ & $3,488,940$ & $3,092,281$ \\
\hline Move in & 34,327 & 37,993 & 41,994 & 37,355 & 46,076 & 49,515 & 45,268 & 42,277 \\
\hline \multicolumn{9}{|l|}{ Job destruction: } \\
\hline Contraction & $1,102,839$ & 965,717 & $1,030,221$ & 994,987 & 973,018 & 901,333 & $1,134,032$ & $1,410,608$ \\
\hline Death & $2,781,915$ & $3,086,093$ & $2,965,193$ & $2,909,694$ & $2,648,325$ & $2,682,980$ & $2,640,929$ & $2,870,695$ \\
\hline Move out & 78,340 & 74,287 & 68,292 & 59,932 & 66,034 & 55,731 & 56,503 & 53,070 \\
\hline \multicolumn{9}{|l|}{$\begin{array}{l}\text { B. Employment change } \\
\text { decomposition }\end{array}$} \\
\hline Employment change = & $-152,995$ & 47,946 & 175,541 & 271,323 & 550,122 & $1,119,709$ & $1,637,269$ & 663,137 \\
\hline (expansion-contraction) & 31,764 & 254,964 & 450,063 & 747,570 & 901,175 & $1,032,186$ & 800,493 & 452,344 \\
\hline+ (birth-death) & $-140,746$ & $-170,724$ & $-248,224$ & $-453,670$ & $-331,095$ & 93,739 & 848,011 & 221,586 \\
\hline$+($ move in-move out) & $-44,013$ & $-36,294$ & $-26,298$ & $-22,577$ & $-19,958$ & $-6,216$ & $-11,235$ & $-10,793$ \\
\hline
\end{tabular}


Table 6: Employment Change Decomposition (1992-2002), Various Interval Lengths of Observation

\begin{tabular}{|l|ccccc|}
\hline & 1 year & 2 years & 3 years & 5 years & 10 years \\
\hline Expansion & $39.3 \%$ & $37.9 \%$ & $35.6 \%$ & $33.5 \%$ & $26.7 \%$ \\
Birth & $59.8 \%$ & $61.2 \%$ & $63.5 \%$ & $65.5 \%$ & $72.2 \%$ \\
In-migration & $0.8 \%$ & $0.9 \%$ & $0.9 \%$ & $1.0 \%$ & $1.1 \%$ \\
\hline Gross creation & $17,096,718$ & $15,847,399$ & $13,514,768$ & $13,000,185$ & $10,160,780$ \\
\hline Contraction & $32.1 \%$ & $29.7 \%$ & $27.5 \%$ & $25.3 \%$ & $20.7 \%$ \\
Death & $66.4 \%$ & $68.8 \%$ & $70.9 \%$ & $73.1 \%$ & $77.5 \%$ \\
Out-migration & $1.4 \%$ & $1.5 \%$ & $1.7 \%$ & $1.6 \%$ & $1.9 \%$ \\
\hline Gross destruction & $15,962,951$ & $14,713,632$ & $11,759,171$ & $11,866,418$ & $9,027,013$ \\
\hline Net change & $1,133,767$ & $1,133,767$ & $1,755,597$ & $1,133,767$ & $1,133,767$ \\
\hline
\end{tabular}

For three-year intervals the analysis is limited to 1992-2001, which can be divided into period of 3 years length.

Table 7: Comparisons with ES-202 Data for West Virginia

\begin{tabular}{|l|cccccc|}
\hline & $\begin{array}{c}\text { NETS, CA, } \\
1992-2002\end{array}$ & $\begin{array}{c}\text { ES-202, WV, } \\
1990-1994\end{array}$ & $\begin{array}{c}\text { NETS, CA, } \\
1992-2002\end{array}$ & $\begin{array}{c}\text { ES-202, WV, } \\
1990-1994\end{array}$ & $\begin{array}{c}\text { NETS, CA, } \\
1992-2001\end{array}$ & $\begin{array}{c}\text { ES-202, WV, } \\
1990-1994\end{array}$ \\
\hline & 1 year & 1 year & 2 years & 2 years & 3 years & 3 years \\
\hline Share of job creation & & & & & & \\
Expansion & $39.3 \%$ & $60.2 \%$ & $37.9 \%$ & $51.1 \%$ & $35.6 \%$ & $44.2 \%$ \\
Birth & $59.8 \%$ & $39.8 \%$ & $61.2 \%$ & $48.9 \%$ & $63.5 \%$ & $55.8 \%$ \\
In-migration & $0.8 \%$ & N.A. & $0.9 \%$ & N.A. & $0.9 \%$ & N.A. \\
Share of job destruction & & & & & & \\
Contraction & $32.1 \%$ & $59.4 \%$ & $29.7 \%$ & $47.3 \%$ & $27.5 \%$ & $39.8 \%$ \\
Death & $66.4 \%$ & $40.6 \%$ & $68.8 \%$ & $52.6 \%$ & $70.9 \%$ & $60.2 \%$ \\
Out-migration & $1.4 \%$ & N.A. & $1.5 \%$ & N.A. & $1.7 \%$ & N.A. \\
\hline
\end{tabular}

The estimates for West Virginia using the ES-202 data are from Spletzer (2000). 
Table 8: Business Establishment Dynamics and Employment Change by Industry, 1992-2002

\begin{tabular}{|c|c|c|c|c|c|c|c|c|c|c|}
\hline \multirow[b]{2}{*}{ SIC Codes } & \multirow[b]{2}{*}{ Major Industry Title } & \multicolumn{4}{|c|}{ Net employment change, 1992-2002 } & \multicolumn{4}{|c|}{ Net change, share of 1992} & \multirow{2}{*}{$\begin{array}{l}\text { Average } \\
\text { Annual } \\
\text { Pay, } \\
2000^{1}\end{array}$} \\
\hline & & Total & $\begin{array}{l}\text { Exp.- } \\
\text { Con. }\end{array}$ & $\begin{array}{l}\text { Birth- } \\
\text { Death }\end{array}$ & Move & Total & $\begin{array}{l}\text { Exp.- } \\
\text { Con. }\end{array}$ & $\begin{array}{l}\text { Birth- } \\
\text { Death }\end{array}$ & Move & \\
\hline $01-97$ & All Industries ${ }^{2}$ & $1,104,192$ & 850,749 & 312,597 & $-59,154$ & $6.7 \%$ & $5.2 \%$ & $1.9 \%$ & $-0.4 \%$ & $\$ 41,182$ \\
\hline $15-17$ & Construction & 43,252 & 136,366 & $-89,936$ & $-3,178$ & $5.6 \%$ & $17.8 \%$ & $-11.7 \%$ & $-0.4 \%$ & $\$ 40,360$ \\
\hline \multirow[t]{3}{*}{$20-39$} & Manufacturing & $-218,996$ & 136,247 & $-340,583$ & $-14,660$ & $-8.9 \%$ & $5.5 \%$ & $-13.8 \%$ & $-0.6 \%$ & $\$ 57,695$ \\
\hline & high-wage manufacturing ${ }^{3}$ & $-26,763$ & 44,354 & $-65,024$ & $-6,093$ & $-2.6 \%$ & $4.4 \%$ & $-6.4 \%$ & $-0.6 \%$ & $\$ 91,278$ \\
\hline & low-wage manufacturing ${ }^{3}$ & $-192,233$ & 91,893 & $-275,559$ & $-8,567$ & $-13.3 \%$ & $6.3 \%$ & $-19.0 \%$ & $-0.6 \%$ & $\$ 35,953$ \\
\hline $40-49$ & Transportation and Public Utilities & 98,406 & 23,980 & 83,878 & $-9,452$ & $11.4 \%$ & $2.8 \%$ & $9.8 \%$ & $-1.1 \%$ & $\$ 47,278$ \\
\hline $50-51$ & Wholesale Trade & 42,600 & 126,812 & $-77,735$ & $-6,477$ & $4.5 \%$ & $13.3 \%$ & $-8.1 \%$ & $-0.7 \%$ & $\$ 48,935$ \\
\hline $52-59$ & Retail Trade & 184,508 & 78,444 & 106,556 & -492 & $7.3 \%$ & $3.1 \%$ & $4.2 \%$ & $0.0 \%$ & $\$ 21,815$ \\
\hline $60-67$ & Finance, Insurance, and Real Estate & 114,011 & 81,421 & 55,721 & $-23,131$ & $9.6 \%$ & $6.9 \%$ & $4.7 \%$ & $-1.9 \%$ & $\$ 60,163$ \\
\hline \multirow[t]{3}{*}{$70-89$} & Services & 954,064 & 338,065 & 616,479 & -480 & $15.2 \%$ & $5.4 \%$ & $9.8 \%$ & $0.0 \%$ & $\$ 41,372$ \\
\hline & high-wage services ${ }^{4}$ & 423,900 & 154,817 & 264,196 & 4,887 & $17.8 \%$ & $6.5 \%$ & $11.1 \%$ & $0.2 \%$ & $\$ 54,484$ \\
\hline & low-wage services ${ }^{4}$ & 530,164 & 183,248 & 352,283 & $-5,367$ & $13.6 \%$ & $4.7 \%$ & $9.0 \%$ & $-0.1 \%$ & $\$ 29,690$ \\
\hline
\end{tabular}

${ }^{1}$ Source: Quarterly Census of Employment and Wages (QCEW), downloaded from http://www.calmis.cahwnet.gov/file/es202/cew-select.htm (viewed on March 1, 2006). 2000 was the last year QCEW classified industries by SIC code; it has shifted to the NAICS code since then. For 2\% of the establishments whose SIC code changed over time, we regard them as belonging to the industry in which they are classified for the most number of years. In the event that an establishment is classified in two industries for an equally long period of time, the more recent of the two industries is chosen. High-wage (and low-wage) industries represent a grouping of SIC2 sub-sectors which fall above (or below) the average salary for that industry.

${ }^{2}$ Excludes unclassified establishments (SIC 99).

${ }^{3}$ SIC Codes: high-wage manufacturing $(28,29,35,36,38)$; low-wage manufacturing $(20,21,22,23,24,25,26,27,30,31,32,33,34,37,39)$.

${ }^{4}$ SIC Codes: high-wage services $(73,78,81,87,89)$; low-wage services $(70,72,75,76,79,80,82,83,84,86,88)$. 